Revista de Derecho Público: Teoría y Método

\title{
LA TÓPICA COMO MÉTODO EN EL DERECHO PÚBLICO*
}

\author{
TOPICAL METHOD AND PUBLIC LAW
}

\author{
Silvia Díez Sastre \\ Profesora de Derecho Administrativo \\ Universidad Autónoma de Madrid
}

RESUMEN: La tópica, acuñada por Aristóteles en el marco del Organon, tuvo una importante influencia en la elaboración del Derecho en los siglos posteriores, especialmente en la Edad Media. La recopilación de catálogos de tópicos condujo a la creación de libros de máximas jurídicas, que constituyeron el estadio inicial de sistematización del Derecho. La tópica fue, así, una pieza fundamental en la configuración de los sistemas jurídicos contemporáneos. Sin embargo, desde 1700 y, muy especialmente, en el siglo XIX, las corrientes sistematizadoras del Derecho continental desacreditaron el método tópico, dejándolo de lado. Tras la Segunda Guerra Mundial, Theodor Viehweg reivindicó la importancia de la tópica en la metodología jurídica, visibilizando las disfunciones derivadas de una aproximación puramente lógico-formal al Derecho. Esta construcción evolucionó hacia las teorías de la argumentación jurídica que han alcanzado un alto grado de desarrollo en la actualidad. Sin embargo, el valor de la tópica en la metodología contemporánea del Derecho y, en especial, del Derecho público, no se ha analizado en profundidad. Este estudio realiza una aproximación en este sentido y propone el reconocimiento de un espacio para la tópica compatible con otros enfoques metodológicos. Para ello se analiza el valor metodológico de la tópica partiendo de la distinción entre tópicos formales y tópicos materiales.

* Este trabajo es fruto de una estancia de investigación realizada entre los meses de julio y octubre de 2019 en la Cátedra del profesor Martin Burgi en la Ludwig-Maximilians-Universität München y financiada con una beca José Castillejo. Las versiones preparatorias se expusieron en el Workshop Öffentliches Recht de la citada Universidad el 9 de octubre de 2019, así como en el Seminario de Teoría y Método (STEM) celebrado el 29 de noviembre de 2019 en la Universidad de Navarra. Agradezco sinceramente las observaciones y críticas que se formularon en ambos seminarios, con las que he tratado de mejorar el artículo que aquí se presenta.

Con el objetivo de facilitar las remisiones internas en el texto, se han numerado los párrafos. Para referirse a ellos se empleará la siguiente fórmula indicando el número del párrafo o párrafos referidos: $[\$]$ o $[\$ \$]$. 
PALABRAS CLAVE: tópica; lugares comunes; método jurídico; sistema jurídico; Derecho público.

ABSTRACT: Topics, coined as part of the Aristotelian Organon, had a major influence on the development of law in later centuries, especially in the Middle Ages. The compilation of common places (or Topics) in catalogs led to the design of legal maxims books, which constituted the initial stage of Law systematization. Topics thus played a fundamental role in shaping contemporary legal systems. However, since 1700 and, particularly, in the 19th century, the systematizing trends of civil law discredited and superseded the topical method. After World War II, Theodor Viehweg advocated the importance of Topics in legal methodology, rendering visible the dysfunctions arising from a purely logical-formal approach to law. This construction evolved into theories of legal argumentation that have reached a high degree of development nowadays. However, the value of Topics in the contemporary methodology of Law and, particularly, of Public Law, has not been analyzed in depth. This paper makes an approach in this regard, and claims a space for Topics compatible with other methodological approaches. For this purpose, an analysis of the methodological value of the topic is carried out and a distinction between formal common places and material Topics is drawn.

KEYWORDS: topics; common places; legal method; legal system; public law.

SUMARIO: 1. PUNTO DE PARTIDA. 1.1. Planteamiento. 1.2. Cautelas.-2. IDEAS COMUNES SOBRE LA TÓPICA JURÍDICA. 2.1. El pensamiento tópico se opone al pensamiento sistemático. 2.2. La tópica jurídica se sitúa en un plano aplicativo del Derecho. 2.3. La tópica es incompatible con las exigencias del Derecho. 2.4. La tópica jurídica no es un método.-3. CARACTERIZACIÓN DE LA TÓPICA JURÍDICA. 3.1. Tipos de tópica. 3.2. Herramientas. 3.2.1. Tópicos formales. 3.2.2. Tópicos materiales. 3.3. Invención y consenso. 3.4. Ámbito de aplicación. 3.5. Valor metodológico. 3.5.1. ¿La tópica como método en la actualidad? 3.5.2. La tópica en la creación de Derecho positivo. 3.5.3. La tópica en la ordenación del Derecho.—4. TÓPICA JURÍDICA Y DERECHO PÚBLICO. 4.1. La función tópica de los conceptos jurídicos. 4.2. Las técnicas tópicas de solución de problemas jurídicos. 4.3. Aforismos y máximas en el Derecho público.-5. NOTA BIBLIOGRÁFICA.

\section{PUNTO DE PARTIDA}

\subsection{Planteamiento}

1. La tópica se acuñó por Aristóteles y se desarrolló por Cicerón en el marco de la argumentación retórica. Conforme a sus construcciones, los problemas que admiten distintas soluciones y que no se refieren a verdades inamovibles pueden resolverse apelando a argumentos aceptados por la comunidad, los denominados lu-

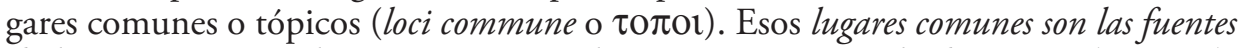
de las que se extraen los argumentos con los que participar en la discusión; algunos de los tópicos entendidos en esta clave son, entre otros: el género, la especie, la causa, el efecto o la definición. Esta técnica jugó un papel fundamental en el ámbito jurídico desde el Digesto justinianeo hasta la Edad Media. Utilizando el razonamiento tópico se elaboraron diversos catálogos de tópicos jurídicos. A partir de ellos comenzaron 
a aparecer libros de máximas jurídicas, que ya no contenían en puridad argumentos con los que buscar el consenso, sino reglas cerradas para la resolución de conflictos que se transmitían en la forma de brocardos o aforismos -por ejemplo, venire contra factum proprium non valet o quien puede lo más puede lo menos-

2. Esta arraigada tradición del pensamiento tópico comenzó a derrumbarse en los albores de 1700 en el contexto jurídico continental (SCHRÖDER, 2012: 123 ss.). El descrédito de la tópica como forma de pensamiento se consolidó en los siglos posteriores: la tópica sirve para charlar, según Descartes, Kant y Hegel (OTTE, 1970: 187; KRIELE, 1976: 115-116; REHBOCK, 1988: 2). La racionalización del Derecho mediante los postulados de la escuela de la exégesis -representada por Montesquieu-y la jurisprudencia de conceptos -del primer Jhering- trató de eliminar el componente subjetivo en la aplicación del Derecho; por su parte, la corriente de purificación del Derecho -culminada en la obra de Hans Kelsen- persiguió la supresión de todas las consideraciones extrajurídicas, que se consideraban ajenas a la disciplina. En esa tarea de construcción sistemática primero y de depuración del Derecho después, la tópica no parecía tener cabida. El problema de la búsqueda de premisas a partir de lugares comunes y de justificación de las decisiones jurídicas no merecía mayor consideración (MORELLI, 2002: 59). Lo relevante era la construcción del sistema y la interpretación de las normas en un momento en que el Estado asumía el monopolio de la producción del Derecho y el material jurídico se ordenaba en torno a categorías jurídicas elaboradas racionalmente.

3. En este contexto, tras la Segunda Guerra Mundial, se abrió un debate en Alemania en el que la tópica pareció aflorar como un método capaz de desplazar o, como mínimo, complementar, al método jurídico clásico, la dogmática jurídica -que ya era objeto de numerosas críticas en ese momento (VIEHWEG, 1995: 212, 213; MANSON, 1977: 196; COFRÉ LAGOS, 2002: 40; GARCÍA AMADO, 2019). La publicación de la obra de Theodor Viehweg, Topik und Jurisprudenz (1953), acaparó la atención de los estudiosos de la metodología jurídica de forma inmediata y con una intensidad poco común (BÖCKENFÖRDE, 1964: 517; HORN, 1967: 601; BOKELOH, 1973: 2). La tópica se convirtió en un concepto de moda que resurgió más allá del Derecho, en la filosofía, la sociología, la literatura y las ciencias políticas (ZIPPELIUS, 1967: 2229; REHBOCK, 1988: 6 ss.; GARCÍA AMADO, 2019).

4. El punto de partida del debate abierto por Viehweg se centra en el error que, a su juicio, había cometido la tradición jurídica continental al aislar el pensamiento sistemático de cualquier otra forma de pensamiento (VIEHWEG, 1995: 134). Considera que el Derecho es una forma de pensamiento problemático (aporético), que se enfrenta al problema fundamental de garantizar la justicia en cada caso. Con ese fin, debe buscar las premisas con las que resolver los problemas jurídicos. En esa tarea puede ayudarse de los tópicos, que son lugares comunes, argumentos aceptados en la comunidad jurídica, tal y como se habían configurado en la Antigüedad. Para fundamentar esta propuesta, Viehweg utiliza argumentos de autoridad y una justificación eminentemente histórica. Acude a la tópica en Aristóteles, Cicerón, el ius civile, el mos italicus y Vico. 
5. Este planteamiento dio lugar a un vivo debate académico, especialmente ligado al acervo del Derecho privado, que se prolongó durante dos décadas. La tópica jurídica se abrió paso como un nuevo camino entre la escuela sistemática y la sociológica (COING, 1955: 436; OPPERMANN, 1985: 1). Se discutió sobre la condición de método de la tópica, así como sobre su posible encaje con algunas de las exigencias fundamentales del Derecho (vinculatoriedad, igualdad y certeza). Sin embargo, la pluralidad de interpretaciones y la incapacidad para acordar un concepto compartido de tópica condujeron a la disolución del debate en la década de los setenta del siglo pasado (LAUNHARDT, 2010: 9). El principal valor reconocido a la tópica de Viehweg fue ser una de las precursoras de las teorías de la argumentación jurídica y, en concreto, de la nueva retórica (GASCÓN Y GARCÍA, 2005: 87 ss.; ATIENZA, 2013: 30).

6. En la actualidad, se han ofrecido tres acepciones principales de la tópica: a) forma de racionalización de la búsqueda de premisas necesarias para la argumentación a partir de catálogos de puntos de vista; b) forma de reconocimiento de validez basada en el consenso y la discusión; y c) forma de razonamiento opuesta al sistema y determinada por la conformación del problema (OTTE, 1970: 184; RODRÍGUEZ PUERTO, 2001: 364). La primera de las acepciones podría adscribirse al humanismo jurídico; la segunda es propia de las teorías de la argumentación jurídica; y la tercera se ha identificado tradicionalmente con la obra de Viehweg, aunque el propio autor matizó a lo largo de su obra la incompatibilidad entre pensamiento tópico y pensamiento sistemático. Como se verá a lo largo de este trabajo, la acepción propia de las teorías de la argumentación jurídica parece ser la más adecuada para describir el funcionamiento de la tópica en la actualidad, sin perder de vista la importancia del proceso de invención en la búsqueda de premisas y de utilización de tópicos en la caracterización de la tópica frente a otras aproximaciones metodológicas.

7. Como consecuencia de esta dilatada trayectoria histórica, la tópica es capaz de explicar numerosas actividades jurídicas, pero ninguna de ellas de forma suficiente (como señala acertadamente, a mi juicio, GARCÍA AMADO, 2019). Está presente en el origen tanto del legal reasoning anglosajón (PERELMAN, 1980: 130), como de los embrionarios sistemas jurídicos que se desarrollaron en la tradición continental (BOKELOH, 1973: 15; KRIELE, 1976: 145). Esta circunstancia dificulta considerablemente su análisis y valoración crítica en la actualidad. A diferencia de la aproximación clásica de la dogmática jurídica, que -a pesar de sus carencias- ofrece las certezas propias de la construcción lógica-sistemática, la tópica se percibe como un concepto vago, escurridizo, aunque muy sugerente. Qué es la tópica y qué son los tópicos en el Derecho continental no es una cuestión a la que pueda responderse de forma unívoca; es preciso atender al contexto histórico y a los distintos autores. Y es una pregunta que está todavía más abierta en el contexto del Derecho público, puesto que los trabajos de tópica jurídica se refieren en su mayoría al Derecho privado, con algunas excepciones referidas al Derecho constitucional (por ejemplo, BÖCKENFÖRDE, 1964: 517), que no puede considerarse, en puridad, parte integrante del Derecho público (VELASCO, 2014: 81 ss.). 
8. En este escenario, el trabajo que se presenta tiene por finalidad identificar qué es la tópica y para qué sirve, en su caso, en el Derecho público contemporáneo continental. En concreto, trata de establecer si la tradición tópica aporta algún valor añadido a las aproximaciones metodológicas del Derecho público elaboradas hasta el momento en el contexto de la dogmática jurídica y la construcción sistemática. Por esa razón no se centra en el análisis de la tópica en el marco de las teorías de la argumentación jurídica, que pivotan fundamentalmente en torno al papel del juez y se refieren normalmente al Derecho privado y, en algunos casos, al Derecho constitucional; sin perjuicio de que se hagan referencias puntuales a las mismas. Con ese objetivo, en primer lugar, se hace un esfuerzo por exponer críticamente las ideas extendidas -no siempre justificadas- sobre la tópica jurídica (2). A continuación, se realiza una propuesta de caracterización de la tópica a partir de un análisis sobre su función, herramientas, ámbito de aplicación y valor metodológico (3). Por último, con base en esos presupuestos teóricos, se tratan de identificar algunas de las manifestaciones más importantes de la tópica en el Derecho público contemporáneo (4).

\subsection{Cautelas}

9. Antes de iniciar la exposición, conviene formalizar algunas cautelas que, a mi juicio, deben preceder a la lectura de cualquier trabajo relacionado con la tópica jurídica. La primera se refiere a los conceptos de tópica y tópicos, respectivamente; la segunda, de más calado, alude a la posible confusión en los trabajos de tópica jurídica del objeto (el Derecho) con el método o la técnica (la tópica).

10. En relación con la primera cautela, hay que tener en cuenta que la tópica es un concepto antiguo -creado por Aristóteles en el marco de la retórica-, que no se configuró en origen como un concepto jurídico. No es hasta la Edad Media cuando la tópica aparece ligada al Derecho en un contexto y con una finalidad que no se corresponden con las circunstancias del Derecho en la actualidad. Además, la tópica ha influido de forma muy distinta en el desarrollo de las tradiciones anglosajona y continental. El common law no ha aspirado en ningún momento a la construcción de un sistema cerrado en sentido estricto ni al tratamiento lógico-formal del Derecho. La búsqueda de la justicia en cada caso se ha apoyado, por el contrario, en la argumentación, otorgando un papel fundamental al juez y controlando su actividad con base en un modelo de precedentes vinculantes que, no obstante, confieren orden y cierta sistematicidad al modelo (SCHAUER, 2004: 199 ss.). De manera que podría llegar a considerarse que es más sencillo encontrar el rastro de la tradición tópica que en el civil law, donde, a mi juicio, se ha hecho un esfuerzo activo por ocultarla.

11. Esta larga evolución del concepto de tópica, asi como los distintos efectos de su traslación al ámbito juridico pueden plantear problemas a la hora de definir su significado y de determinar sus funciones a día de hoy (BOKELOH, 1973: 2). A ello se suma el hecho de que -en la tradición continental- la idea de tópica jurídica está fuertemente condicionada por la obra de Theodor Viehweg y el debate que suscitó, esencialmen- 
te, en Alemania. Desde un punto de vista conceptual, Viehweg utiliza los términos de tópica y tópicos, pero no les dota de una intensión clara. Ya se ha señalado que acude a los estudios de la tópica desde la Antigüedad [supra \$ 4], pero se aleja del significado de tópica manejado en ellos sin proponer un nuevo concepto. El resultado es una falta de selección de las notas definitorias de la tópica y de los tópicos, que ha dificultado la comunicación entre los juristas desde entonces. Además, ha ampliado la extensión del concepto de tópica, incluyendo casi cualquier forma de actividad jurídica que no se identifique con el pensamiento sistemático.

12. Por otro lado, hay que tener en cuenta que la palabra "tópico" está fuertemente connotada en el lenguaje común. Se habla de tópicos para referirse a expresiones triviales o muy empleadas, que pueden contener clichés o mitos sobre una materia. En el ámbito jurídico existen numerosos tópicos de este tipo; así, por ejemplo, la idea francesa de que el juez administrativo -por definición- no juzga (TOUZEIL-DIVINA, 2019: 225 ss.). Por estas razones, la utilización de los términos tópico y tópica en un contexto técnico-jurídico puede dar lugar a confusión, en la medida en que, en parte, se aleja notablemente de ese significado -como se verá a lo largo del texto-. Ello justifica plantear la pregunta de qué es la tópica en la actualidad y en qué consiste el método tópico (BLÜHDORN, 1970: 312) en el Derecho público. La respuesta exige la formulación previa de una propuesta conceptual que ayude a determinar qué son la tópica y los tópicos y para qué sirven.

13. La segunda cautela está directamente relacionada con el silogismo elaborado por Viehweg identificando tópica y Derecho: si la tópica es la técnica del pensamiento de problemas y la jurisprudencia es la técnica al servicio de una aporía-la pregunta por la justicia-, entonces la jurisprudencia es tópica (GARCÍA AMADO, 2019). Consciente de esa errónea identificación entre objeto y método, Viehweg afirma que "la jurisprudencia no puede convertirse en un método" porque la tópica ha prestado grandes servicios a la jurisprudencia y es tópica en sí misma (VIEHWEG, 2007: 123). Esta confusión entre objeto y método no es exclusiva de Viehweg ni de la tópica. Cicerón señalaba que para conocer una materia era preciso conocer sus tópicos, pues de ellos se extrae el material necesario para la demostración (VIEHWEG, 2007: 49). Y desde el siglo XIX puede afirmarse que la elaboración académica del Derecho no solo es un método, sino también una posible fuente de Derecho en determinados momentos y contextos (SCHRÖDER, 2012:1). Puede afirmarse, por tanto, que esta confusión ha sido habitual en la metodología jurídica, aunque no por ello ha sido, ni es, menos problemática.

14. También en la dogmática jurídica los conceptos pasan a formar parte del propio material jurídico que es objeto de estudio -por ejemplo, el concepto de acto y norma se elabora doctrinalmente y se incorpora al Derecho positivo, pasando a integrar el material jurídico-. Y lo mismo sucede con la tópica, especialmente a lo largo de su evolución histórica anterior al desarrollo del método jurídico del siglo XIX. La tópica jurídica medieval condujo a la elaboración de catálogos de tópicos, aforismos y máximas que, cuando lograron un cierto grado de aceptación, sirvieron como yacimiento de soluciones jurídicas para la elaboración de normas jurídicas (fuente del Derecho) 
y también como herramienta para realizar una rudimentaria ordenación del Derecho (método jurídico). Por esa razón, Viehweg llega a considerar al Derecho como tópica en sí mismo. No es fácil establecer la línea de separación entre el método que ha llevado a la creación del Derecho y el Derecho en sí. Esta cuestión se desarrollará más adelante al analizar el valor metodológico de la tópica en el Derecho [\$\$ 46 ss.]. En este punto es fundamental subrayar esta ambivalencia de la tópica y los tópicos en el ámbito jurídico, que debe manifestarse en planos metodológicos y parámetros de análisis distintos. La naturaleza y límites de la utilización de la tópica -especialmente en el Derecho público- deberán variar en función de su condición de posible método jurídico o de Derecho mismo.

\section{IDEAS COMUNES SOBRE LA TÓPICA JURÍDICA}

15. Tras la exposición de las cautelas relacionadas con los trabajos sobre la tópica jurídica, hay que analizar las ideas comunes y más extendidas en la actualidad sobre la tópica jurídica. En ocasiones, estas ideas son más bien prejuicios e, incluso, clichés -tópicos en el sentido vulgar del término-, que se han derivado, fundamentalmente, de la obra de Viehweg sobre la tópica. Creo que esas ideas pueden llegar a lastrar el estudio de la tópica de forma analítica. Por esa razón, merece la pena detenerse en su exposición y crítica, con el fin de realizar después una propuesta de caracterización de la tópica jurídica contemporánea.

\subsection{El pensamiento tópico se opone al pensamiento sistemático}

16. Viehweg presenta a la tópica como una forma del pensamiento jurídico contemporáneo (COING, 1955: 442; LAUNHARDT, 2010: 7). Para fundar su propuesta, acude a la tópica antigua como desarrollo de la retórica, en concreto, como parte de la tópica aristotélica contenida en el Organon. La tópica, así caracterizada, se refiere a los razonamientos dialécticos que se realizan en el plano de lo opinable (ARISTÓTELES, 2011: 215 ss., 327 ss.; VIEHWEG, 2007: 29, 37 ss.). Esta búsqueda de la tópica en los textos antiguos tiene su origen en el planteamiento de Giambatistta Vico que, en su obra De nostri temporis studiorum ratione (1708), diferencia entre el método antiguo, la tópica, y el nuevo método cartesiano, que opera al modo de la geometría. Con base en esa distinción, Viehweg elabora una dicotomía conceptual de pares opuestos: la tópica es lo contrario al sistema, en clave de metodología jurídica académica. De hecho, su pensamiento se apoya, paradójicamente, en numerosas dicotomías conceptuales al estilo de la jurisprudencia de conceptos (Begriffsjurisprudenz) a la que Viehweg se oponía con su propuesta tópica (al respecto, RODRÍGUEZ DE SANTIAGO, 2002: 1288)-.

17. La oposición entre tópica y sistema parte de entender que, en realidad, no es posible establecer premisas verdaderas de las que obtener deducciones en cadena en el ámbito jurídico, porque el Derecho es tópico (VIEHWEG, 2007: 32 ss.). El in- 
tento de ordenar el material jurídico en un sistema sería, así, una aspiración deseable (incluso para VIEHWEG, 2007: 74), pero irrealizable por la propia naturaleza del Derecho. La tópica formula, de este modo, una critica fundamental a la finalidad del pensamiento sistemático. La orientación a la perfección del sistema altera las cadenas deductivas y conduce a un alto grado de abstracción y de separación del problema. Además, conduce a una sesgada selección de las cuestiones que son objeto de análisis con base en una finalidad establecida de forma apriorística (VIEHWEG, 2007: 74). En esa línea, Viehweg quiere demostrar que el Derecho siempre ha sido tópico, salvo durante el paréntesis en que se intentó transformar en un sistema lógico-deductivo (comparte esta idea GARCÍA DE ENTERRÍA, 2007: 15; la critica LARENZ, 2001: 152). Desde su punto de vista, no tiene ninguna utilidad tratar de ordenar los conceptos y proposiciones jurídicas entre sí de forma lógico-deductiva. Deben estar lo más cerca posible del problema (DIEDERICHSEN, 1966: 697).

18. La orientación al problema en lugar de al sistema hace de la tópica una técnica del pensamiento problemático (Problemdenken) que se opone al pensamiento sistemático (Systemdenken) (VIEHWEG, 2007: 56). Esa idea no es original de Viehweg; la toma de Nicolai Hartmann. Sin embargo, este autor ni se refería al ámbito jurídico -sino a la filosofía-, ni pretendía excluir una forma de pensamiento frente a otra (BOKELOH, 1973: 55). En realidad, la oposición frontal al sistema no puede considerarse una de las notas definitorias de la tópica. Solo Viehweg plantea esa incompatibilidad, que se suaviza en determinados pasajes de Tópica y Jurisprudencia y que se matiza abiertamente en otros momentos de su obra -así, cuando expone el método retórico, antiguo, identificado con la tópica y el método nuevo, crítico, del racionalismo cartesiano, señala que ambos modos deben intercalarse (VIEHWEG, 2007: 35)-. En general, se ha aceptado que la tópica cumple un papel de complemento del pensamiento sistemático (CANARIS, 1983: 151; VIEHWEG, 2007: 74, 133; DIEDERICHSEN, 1966: 705). Concretamente, en el plano académico, se entiende que la tópica se ubica en un momento distinto -anterior- a la elaboración del sistema (WEINBERGER, 1973: 25).

19. Más allá de la falsa oposición entre tópica y sistema, en las críticas de los defensores de la tópica al enfoque sistemático subyacen dos ideas de interés con una fuerte carga axiológica. La primera idea es la búsqueda de la justicia a través del Derecho; dicho de otro modo, la justicia se plantea como el fin principal del Derecho en cada caso (COING, 1993: 295). La segunda idea es la sinceridad de los estudios metodológicos sobre el modo en que verdaderamente se elabora y se trabaja con el Derecho en la práctica, especialmente por los jueces (HORN, 1967: 608; BLÜHDORN, 1970: 270; LAUNHARDT, 2010: 9). Estas dos ideas están acompañadas de la necesidad de buscar la aceptación por la comunidad jurídica de las premisas que han de guiar sus razonamientos, alejándose, así, de los razonamientos lógico-deductivos y, prácticamente, automáticos, a los que se había aspirado en la tradición alemana del siglo XIX. En esta propuesta de razonamiento jurídico puede entreverse un elemento consensual y democrático que pretende romper con la tradición positivista, formalista (GARCÍA AMADO, 2019) y, podría añadirse, autoritaria, anterior. Asimismo, 
se aprecia una clara influencia del common law (ESSER, 1990; VIEHWEG, 2007: 82) y, en concreto, del realismo jurídico norteamericano (OPPERMANN, 1985: 42 ss.). Pero esa influencia apenas suele reconocerse expresamente por los defensores de la tópica. Se deja de lado a la literatura anglosajona, en la que se podría haber encontrado un mayor desarrollo de los argumentos que se utilizan para defender la tópica como forma de aproximación al Derecho.

\subsection{La tópica jurídica se sitúa en un plano aplicativo del Derecho}

20. Partiendo de la distinción entre aplicación y teoría (ciencia) del Derecho (JHERING, 2005: 177), puede decirse, de forma intuitiva, que la tópica se asienta en un plano metodológico aplicativo. La forma de pensar tópica parece ser la que mejor describe el trabajo de los juristas en la práctica (DIEDERICHSEN, 1966: 697). No en vano, es una técnica orientada a resolver problemas, que es lo que importa en la aplicación del Derecho, no tanto, en principio, en su investigación y ordenación académica. Por esa razón, es habitual que los estudiosos de la tópica se sitúen en un plano aplicativo judicial, destacando, además, la función del juez en la creación del Derecho, que queda oculta a través del pensamiento jurídico axiomático (BOKELOH, 1973: 11, 93). Esa línea de análisis de la tópica ha evolucionado a través de las teorías de la argumentación jurídica, que controlan la discrecionalidad del juez y juegan, así, a favor del Estado de Derecho (BOKELOH, 1973: 36).

21. Sin embargo, Viehweg plantea su obra monográfica sobre la tópica como un estudio que se encuadra en la tradición de la investigación de los fundamentos del Derecho (Rechtsgrundlagenforschung) (VIEHWEG, 2007: 27); esto es, de la explicación teórica de los procedimientos que se siguen en la práctica y en la investigación jurídica (HORN, 1967: 601). Por esa razón, se ha entendido que el nuevo debate sobre la tópica abierto por Viehweg se plantea en el plano de la investigación jurídica, aunque no lo haga con claridad (GALLEGO, 1962: 146; ZIPPELIUS, 1967: 2232); y que la tópica sería más útil en el terreno de la creación de Derecho, donde es necesaria una discusión previa en el marco de los órganos competentes (CANNARIS, 1983: 146; GARCÍA AMADO, 2019). Es cierto, no obstante, que al mismo tiempo Viehweg se refiere a la necesidad de guiar y racionalizar la resolución de problemas concretos, con base en la búsqueda de la justicia y alude al papel del juez. Esa idea de búsqueda de la solución justa en el caso concreto llevaría a situar su propuesta en un momento aplicativo (así lo entendió LARENZ, 2001: 152; también, GARCÍA AMADO, 2019). De manera que no es tan fácil determinar cuál es el plano en el que se sitúan las reflexiones de Viehweg y, en general, el debate sobre la tópica jurídica. A mi juicio, hay que mantener abierto todo el espectro de planos metodológicos de análisis, con el fin de identificar las distintas dimensiones de la tópica que pueden ser de utilidad en la operacionalización, práctica y académica, del Derecho público actual. 


\subsection{La tópica es incompatible con las exigencias del Derecho}

22. Las críticas más duras contra la tópica jurídica se centraron en la vulneración de la exigencia de vinculación al Derecho positivo, al interpretar que busca una legitimación de las decisiones basada en el consenso, incluso más allá de la Ley (CANNARIS, 1983: 143). Si se razona en Derecho con base en argumentos orientados a resolver el problema, parece que el Derecho positivo se pone al servicio del problema hasta el punto de que no es relevante garantizar su aplicación. En consecuencia, se acentúa la independencia judicial frente a la vinculación a la Ley (HORN, 1967: 601). La configuración de la tópica como un mecanismo prácticamente al margen del Derecho positivo impide considerar que el ajuste de las decisiones a las reglas vigentes sea el criterio de rectitud o acierto fundamental de las decisiones jurídicas (LARENZ, 2001: 156); lo que se ha considerado una demostración de que la tópica está anticuada (DIEDERICHSEN, 1966: 702; HORN, 1967: 601). Esta forma de comprender la tópica ha llevado a negar su capacidad para elaborar propuestas vinculantes necesarias en el Derecho (OTTE, 1970: 190). Por esa razón, se afirma que es difícil asumir que la cetética, esto es, la puesta en duda de todas las afirmaciones con un fin investigador, pueda sustituir a la dogmática en el Derecho (sobre la distinción entre cetética y dogmática, VIEHWEG, 1995: 156, 157).

23. En efecto, la tópica no ofrece ningún criterio de ordenación jerárquica de valores o pensamientos. Todas las soluciones jurídicas parecen estar al mismo nivel (DIEDERICHSEN, 1966: 700, 703). Lo que significa que todas las posibles soluciones se presentan como igualmente posibles: cada juez puede elegir un topos adecuado de forma casual y arbitraria (LARENZ, 2001: 156). Por eso se seńala que la tópica renuncia a la garantía de la seguridad y la igualdad en la toma de decisiones (LAUNHARDT, 2010: 39). Ahora bien, aunque Viehweg plantea una tópica al margen del Derecho positivo, no hay que desechar la posibilidad de encontrar algún encaje a la tópica en un contexto positivista, de garantía de la aplicación de las normas del ordenamiento jurídico. En ese caso, la tópica tiene que asumir las preferencias expresadas por el legislador y argumentar anteponiendo las mismas a otros argumentos. Ciertamente, en esos casos se plantea habitualmente el clásico problema de prelación entre los distintos cánones de interpretación de normas (RODRÍGUEZ DE SANTIAGO, 2016: 70 ss.). Esos argumentos se acuñaron históricamente en el ámbito de la tópica, como un mecanismo de control de la creatividad, que deja más flexibilidad y capacidad de adaptación a la realidad que el sistema (VIEHWEG, 1995: 213).

Desafortunadamente, el problema de la vinculación al Derecho y de la selección entre varias soluciones posibles no parece resolverse fácilmente mediante una aproximación sistemática al Derecho o mediante la mera aplicación del Derecho positivo. En el actual escenario de saturación normativa, así como de criterios de interpretación, asistimos precisamente a un contexto en el que parece que cualquier solución puede ser buena. Un buen sector de referencia en este sentido es el Derecho de la contratación pública, donde, incluso en casos de clara expresión de la voluntad del legislador, se acude a diferentes criterios -incluyendo la bondad o no de ciertas decisiones- para defender distintas soluciones jurídicas. La interpretación de la regulación sobre los contratos menores parece constituir un buen ejemplo en este sentido (art. 118 Ley 9/2017, 
de 8 de noviembre, de Contratos del Sector Público). En la práctica muchas veces se asiste a una solución retórica de los problemas que va más allá, si no en contra, en ocasiones, del Derecho positivo.

\subsection{La tópica jurídica no es un método}

24. La última de las ideas extendidas sobre la tópica jurídica es que no es un método jurídico. Viehweg rescata la utilidad de la tópica para el Derecho, pero niega categóricamente su condición de método, al igual que muchos de sus coetáneos (BOKELOH, 1973: 116, 117). Un método debe orientarse a la obtención de conocimiento evaluable racionalmente y debe simplificar la tarea de quien lo aplica. Sin embargo, la tópica solo se dirige a lograr la aceptación de las premisas por el interlocutor con el fin legitimarlas. La aceptación por el interlocutor es el criterio de legitimación o de rectitud de las decisiones y el debate es su única instancia de control (VIEHWEG, 2007: 72). Ello hace que la tópica abra muchas vias de resolución de problemas, a diferencia de la deducción a partir de un sistema (WEINBERGER, 1973: 25), y que no sea lo suficientemente concreta como para determinar por completo los pasos que deben darse en el pensamiento jurídico (BOKELOH, 1973: 121; RODRÍGUEZ DE SANTIAGO, 2002: 1290; LAUNHARDT, 2010: 39).

25. En consecuencia, puesto que la tópica no permite analizar la corrección lógica y objetiva de las soluciones, sino solo su capacidad de persuasión subjetiva (DIEDERICHSEN, 1966: 702; BOKELOH, 1973: 10), no puede considerarse un método (VIEHWEG, 2007: 75). La tópica es una técnica o un estilo, no es método (BOKELOH, 1973: 128). En esta línea, hay que destacar que Viehweg habla en todo momento de Jurisprudenz y no de Ciencia del Derecho (Rechtswissenschaft) -como solía ser lo habitual en los estudios de metodología jurídica en la Alemania de la época-. Esa distinta selección de términos puede relacionarse con el carácter tópico del Derecho, que niega automáticamente su posible caracterización como ciencia (ROBLES, 1985: 116).

26. Ciertamente, la tópica se refiere a un momento de creatividad, de búsqueda de premisas que no se realiza de forma lógica. Por esa razón, se ha afirmado que la tópica es prelógica y se le ha negado la condición de método, puesto que es difícil ordenar esa tarea creativa de búsqueda de puntos de vista y de argumentación (VIEHWEG, 2007: 68; COFRÉ LAGOS, 2002: 38). Pero ese momento de creatividad en la buisqueda de premisas no es exclusivo de la tópica. Cuando se elabora una propuesta de sistema conceptual se eligen unas notas definitorias para la creación de un concepto y no otras, sin que pueda evaluarse únicamente su corrección lógica, sino aspectos como su función en la articulación del pensamiento jurídico, su resonancia o su aceptación en la comunidad jurídica (DÍEZ, 2018a: $\$ \$ 313$ ss.). La tópica alude, así, a la importancia de los usos del lenguaje y a la importancia del auditorio a efectos de lograr la aceptación de las reglas jurídicas (VIEHWEG, 1995: 216), apelando a una realidad que se ha dejado de lado en otros métodos, ocultando su existencia. Además, la negación de su condición de método es puramente formal; del mismo modo que 
su caracterización como técnica no parece ser muy aclaratoria. Viehweg no señala en qué se diferencia un método de una técnica y no parece ser una distinción clara ni muy fructífera. Así que, a mi parecer, lo relevante parece ser determinar el valor metodológico de la tópica, sin necesidad de afirmar si es un método en el sentido del método lógico-formal. Sobre esa cuestión se volverá más adelante [\$\$ 46 ss.].

\begin{abstract}
Hay múltiples ejemplos de construcción conceptual en los que se aprecia la existencia de numerosos momentos de creatividad que no están formalizados mediante los procesos de inducción y deducción en el marco de un sistema cerrado. Así, por ejemplo, en el debate en torno a la creación de un concepto que sirviera para caracterizar y designar a los crímenes cometidos durante el nacionalsocialismo se observa un ejercicio de enorme creatividad y justificación de la selección de las notas definitorias y del término de los conceptos de "genocidio" y de "crímenes contra la humanidad". El resultado fue el triunfo de un concepto frente a otro sin que se puedan conocer con certeza las razones que llevaron a ese éxito de un concepto y al fracaso de otro (LEMKIN, 1946: passim; al respecto, en detalle, SANDS, 2018: passim). La tópica da visibilidad a ese momento de creatividad, de inventio, pero eso no significa que no exista en la utilización de otros métodos. Dicho de otro modo, la existencia de creatividad en la búsqueda de soluciones jurídicas no parecer ser exclusivo de la tópica. Habría que buscar otros elementos que puedan diferenciarla de otras aproximaciones metodológicas.
\end{abstract}

\title{
3. CARACTERIZACIÓN DE LA TÓPICA JURÍDICA
}

27. Tras la exposición de las ideas comunes extendidas sobre la tópica, se propone una caracterización de la tópica jurídica que sirva a los fines de este trabajo: identificar de qué modo la tópica y su tradición de pensamiento pueden explicar mejor que otros enfoques metodológicos algunas de las realidades o fenómenos del Derecho público. Para ello, se trata de encontrar el rastro de la tradición tópica en el Derecho público continental a partir de los elementos que se analizan seguidamente.

\subsection{Tipos de tópica}

28. Viehweg diferencia entre tópica de primer grado y de segundo grado. La primera se refiere a la tarea de invención, de búsqueda de premisas; la segunda alude al trabajo con catálogos de tópicos elaborados previamente. La búsqueda de tópicos se mueve en el terreno de la creatividad y, por tanto, es más difícil de aprehender y de explicar racionalmente con las herramientas de la metodología jurídica en la actualidad; se sitúa más en el espacio de la psicología y la neurociencia, sin que por ello deje de tener relevancia apuntar a ese fenómeno. En otro plano, la aplicación de tópicos ya creados tiene en común con el Derecho que debe enfrentarse a la selección de los tópicos más adecuados para la solución de un problema concreto, como sucede con la aplicación de las normas jurídicas. Sin embargo, a diferencia de estas -por regla general-, los catálogos de tópicos son flexibles y tienen (o deberían tener) una ordenación discrecional (LARENZ, 2001: 153). Hay que tener en cuenta que los catálogos de tópicos surgieron como herramientas para ofrecer posibilidades de argumentación, no para elaborar teóricamente el material jurídico (SCHRÖDER, 2012: 31). Además, los 
tópicos no son vinculantes en sí mismos y solo están dotados de la legitimidad que les otorga el consenso en un momento dado o a lo largo de un periodo determinado. Pretenden estimular la intuición y evitar que se pierda ningún argumento (OTTE, 1970: 186; MÖLLERS, 2019: 495).

29. De lo expuesto se deduce que los catálogos de tópicos cierran la imaginación y condicionan el pensamiento de un modo similar al pensamiento sistemático, al plantear puntos de vista ya dados y aceptados previamente. De hecho, Viehweg es consciente de esto al señalar que "[c] uesta mucho trabajo tocar aquello que ha quedado ya fijado" (VIEHWEG, 2007: 71). En esos casos, considera que la interpretación puede ser útil, facilitando la adaptación a los cambios de situación. Se plantea, así, el mismo problema de interpretación que se plantea en el Derecho ordenado sistemáticamente. Los tópicos entendidos de este modo son elementos de estabilización del pensamiento jurídico, que "favorecen el pensamiento nostálgico" (GARCÍA AMADO, 2019). En eso no son tan diferentes de los conceptos propios de la tradición sistemática. Puede decirse entonces que la tópica de primer grado es más productiva para aludir al pensamiento creativo, pero no es capaz de ordenarlo ni de explicarlo suficientemente. Mientras que la tópica de segundo grado no se aparta tanto del pensamiento sistemático, como podría pensarse a priori. Sobre esta cuestión se vuelve seguidamente, al analizar los tipos de herramientas de la tópica.

\subsection{Herramientas}

30. Acaba de verse que la tópica más desarrollada es la de segundo grado, que consiste en la búsqueda de premisas para resolver problemas utilizando lugares comunes, esto es, puntos de vista aceptados por la comunidad en un momento dado. Lo propio de la tópica parece ser, por tanto, la orientación al problema y la utilización de estas concretas herramientas argumentativas: los tópicos, en el marco del Derecho. En la doctrina cabe encontrar múltiples caracterizaciones y ejemplos de tópicos, que no suelen alcanzar un alto grado de precisión (crítico al respecto, LARENZ, 2001: 154). En especial, cabe destacar el poco interés en analizar la forma en que se presentan los tópicos. Viehweg señala que pueden ser conceptos o proposiciones (VIEHWEG, 2007: 65; BOKELOH, 1973: 7) -no menciona a las instituciones, que fueron una de las formas de reducción del Derecho utilizada por la jurisprudencia de conceptos y que parecen oponerse claramente a la tópica y sus fines (en sentido opuesto, identifica pensamiento tópico e institucional, GARCÍA DE ENTERRÍA, 2007: 18, 23)-. También se ha señalado que los tópicos pueden ser citas conocidas, ejemplos paradigmáticos o argumentos frecuentemente utilizados (DIEDERICHSEN, 1966: 697); o esquemas de argumentos (ATIENZA, 2013: 276).

Viehweg considera que son tópicos las resoluciones de casos que pueden transformarse en un axioma; la categoría de interés creada por Jhering (al respecto, en detalle, MEDINA, 2016: 132 ss.); conceptos jurídicos como el de declaración de voluntad; y principios como el de protección de la confianza (BOKELOH, 1973: 7). También se ofrecen como ejemplos los argumentos a simile, a contrario y a maiore ad minus (VIEHWEG, 2007: 68, 151, 163; HORN, 1967: 604; 
BOKELOH, 1973: 28); y la teoría del enriquecimiento injusto (OTTE, 1970: 186). Otros ejemplos de tópicos son, por ejemplo, los argumentos de: lo más duradero o permanente es mejor que lo mudadizo; el género es preferible a la especie; lo que causa el bien en sí mismo es mejor que lo que lo causa accidentalmente; lo que es absolutamente bueno es mejor que lo que lo es solo en ciertos casos (COFRÉ LAGOS, 2002: 31).

31. Los tópicos, caracterizados de forma tan amplia, son argumentos de razón, basados en la lógica o la justicia natural, cuyo valor está en su capacidad de crear consenso. Son puntos de partida retóricos que no se derivan de un contexto cerrado de deducción, esto es, de un sistema (BOKELOH, 1973: 11; KRIELE, 1976: 118; RODRÍGUEZ PUERTO, 2001: 365; MÖLLERS, 2019: 494). Sin embargo, parece que en los ejemplos de tópicos que se ofrecen se mezclan fenómenos muy diferentes: no parece igual la regla de "quien puede lo más puede lo menos", que el concepto de interés elaborado por Jhering. Es evidente que algunos de ellos son argumentos que convencen con facilidad, entre otras cosas porque suelen estar fuertemente arraigados en la conciencia jurídica colectiva -en muchas ocasiones desde la Edad Media-. Es el caso de las máximas jurídicas, brocardos o aforismos que se desarrollaron en la tradición de la tópica jurídica medieval y que se han ido transmitiendo a lo largo del tiempo, condensando ideas básicas de justicia. Más que de tópicos podríamos hablar de normas jurídicas, porque ofrecen una solución jurídica cerrada y no un argumento con el que buscar una solución. Esta caracterización del trabajo con tópicos está más vinculada a la retórica que al análisis y la discusión de los problemas mediante la búsqueda de distintos puntos de vista. Pero hay otros tipos de tópicos que no ofrecen directamente soluciones, sino que continúan actuando como lugares o fuentes de las que obtener argumentos para el debate, tal y como se utilizaban los tópicos en la Antigüedad. En este caso los tópicos son argumentos con una finalidad principal: orientar o conducir el pensamiento (LARENZ, 2001: 153). Esta función de los tópicos, ligada a su capacidad para articular el debate y los distintos argumentos (muchas veces apoyados en orientaciones principiales del Derecho positivo), parece encajar mejor con las exigencias del Derecho actual que su pura capacidad de persuasión retórica.

32. Viehweg distingue en su obra entre tópicos formales y materiales, aunque no extrae consecuencias relevantes de esa diferenciación. Sin embargo, en el ámbito del Derecho público continental, estas clases de tópicos pueden ser idóneas para distinguir entre los tópicos y las funciones que se les han atribuido a lo largo de la historia, así como para explicar la realidad actual de la utilización de tópicos en el Derecho público, determinando los distintos parámetros de ajuste a Derecho de la solución de problemas apoyada en tópicos. A continuación, se desarrollan brevemente ambos conceptos.

\subsubsection{Tópicos formales}

33. Los tópicos formales son argumentos contenidos en conceptos o proposiciones que tienen valor tópico en sentido aristotélico. Son ideas con capacidad analítica, aceptables universalmente, que ayudan en la búsqueda de puntos de vista, argumen- 
tando en favor y en contra de lo opinable para la solución de problemas (REIMER, 2016: 191). Su valor sistemático es intrascendente (VIEHWEG, 1995: 211; 2007: 44, $65,66)$ porque no contienen en si una solución, sino que ayudan a encontrarla. En esa medida, son estructuras de razonamiento, no tienen contenidos materiales (GARCÍA AMADO, 2019). Los tópicos formales constituirían de este modo, una clase o una categoría a la que puede pertenecer un argumento (KRIELE, 1976: 142). Este tipo de tópicos parece el más adecuado para acomodarse a un contexto, como el actual, en el que la tópica debe convivir con un denso Derecho positivo y con el método jurídico dogmático. La tópica actuaría, de ese modo, como un complemento para la solución de problemas jurídicos, allí donde no haya soluciones previstas previamente en el ordenamiento jurídico o existan ciertos problemas de interpretación.

\begin{abstract}
Aristóteles señala que los tópicos deben clasificarse en torno a cuatro géneros: accidente, género, proprium y definición, que se relacionan con diez categorías: sustancia, cantidad, calidad, relación, lugar, tiempo, estado, posición, acción y pasión (ARISTÓTELES, 2011: 327 ss.). En estas categorías de tópicos puede apreciarse con claridad la inexistencia de una solución previamente dada. Por esa razón, los cánones de interpretación (histórica, gramatical, lógica, sistemática y teleológica), así como la analogía y la argumentación a maiore ad minus y a minore ad maius se consideran tópicos (BRAUN, 2016: 171). Esos tópicos se solían utilizar en la Edad Media junto al Corpus Iuris Civilis (RODRÍGUEZ PUERTO, 2001: 365). De hecho, en la actualidad, los cánones de argumentación se han caracterizado como catálogos de tópicos: semántico, pragmático, histórico, de autoridad, sintáctico, genético, teleológico y ético (BERUMEN, 2015: 543).
\end{abstract}

\title{
3.2.2. Tópicos materiales
}

34. A diferencia de los tópicos formales, los tópicos materiales aluden a aforismos, máximas o reglas que contienen la solución sustantiva para un posible problema. No son guías para la búsqueda de la solución, sino que la ofrecen directamente. Se trata de argumentos cuya corrección se determina de forma externa a la tópica (KRIELE, 1976: 142). Estos tópicos tienen una clara fuerza persuasiva debido a su consolidación a lo largo de los siglos y a la invocación que realizan de máximas que suelen parecer de sentido común o de justicia, apelando a la coherencia, la racionalidad o, incluso, la lógica. Por esa razón no tienen capacidad analítica, pero sí una importante fuerza persuasiva, similar a la costumbre, ya que estos tópicos han sobrevivido a lo largo del tiempo a partir de los catálogos de tópicos medievales. En el ámbito jurídico, son normalmente máximas que condensan la ratio decidendi de cierto tipo de casos, lo que permite su aplicación analógica. Su interpretación o su operacionalización es muy similar a la de las normas del Derecho positivo en la actualidad (BOKELOH, 1973: 29). De hecho, es habitual que se empleen en la jurisprudencia, pasando a formar parte del acervo jurídico. En este sentido, se ha señalado que los tópicos plantean los mismos problemas de aplicación e interpretación que las normas jurídicas (GARCÍA AMADO, 2019).

Ejemplos de tópicos de este segundo tipo podrían ser los siguientes: de minimis non curat praetor; in dubio pro reo; enriquecimiento injusto; lex specialis derogat legi generali, entre otros (GARCÍA AMADO, 2019). 
35. El riesgo que existe en este tipo de tópicos está en su utilización como clichés o ideas superficiales, con una connotación negativa, alejándose de la tradición argumentativa de la tópica en la Antigüedad y la Edad Media (KRIELE, 1976: 146; GARCÍA AMADO, 2019). Los tópicos materiales son, así, fórmulas que resultan de la experiencia y de la tradición y que se legitiman por su antigüedad y por su fórmula lapidaria (COFRÉ LAGOS, 2002: 39; como ejemplo, PEREIRA-MENAUT, 2001: 49 ss.). Este significado enlaza con la idea de tópico en otras disciplinas. En la literatura un tópico es un cliché fijo que tiene dos elementos fundamentales: un pensamiento transmitido a lo largo del tiempo y una expresión lingüística fija. También en la sociología un tópico es una fórmula lingüística que repite un estereotipo (REHBOCK, 1988: 7, 10).

36. En Derecho, aunque no se haya formalizado, también hay un uso similar de los tópicos que encierran reglas jurídicas. Ahora bien, a diferencia de los tópicos formales, estos tópicos no se plantean como argumentos que permitan buscar distintos puntos de vista, sino como máximas que condensan soluciones aplicables a casos concretos. En ese sentido, pueden suscitar más problemas de ajuste con el ordenamiento jurídico, en la medida en que contienen reglas jurídicas. Podría decirse que más que método, son Derecho en sí mismos o pretenden serlo -aludiendo a la cautela expresada al inicio de este trabajo [\$\$ 13-14]-. Por eso, aunque se denominan tópicos -fundamentalmente porque surgieron en un momento en que la tópica era el modo de argumentar en Derecho y crear soluciones jurídicas-, estos argumentos no ayudan a analizar en profundidad los problemas. Por el contrario, resuelven los problemas juridicos superficialmente con base en lugares comunes y frases hechas (BOKELOH, 1973: 17). Los tópicos, entendidos de esta manera, pueden ser engañosos y contener numerosas excepciones que pueden conducir a soluciones indeseables (ATIENZA, 2013: 291). Sobre este tipo de tópicos se vuelve más adelante en relación con el Derecho público $[\$ \$ 70$ ss.].

\subsection{Invención y consenso}

37. De lo expuesto hasta el momento, puede deducirse que la función principal de la tópica contemporánea es poner el foco en el proceso de invención, de búsqueda de premisas, así como en la necesidad de su aceptación por la comunidad jurídica. Desde la Antigüedad la tópica se presenta como una técnica de invención que se apoya en lugares comunes, puntos de vista compartidos, que ayudan a razonar a favor o en contra de determinadas posiciones con el fin de alcanzar una solución aceptable (ATIENZA, 1999: 43). La tópica es, así, invención por contraposición a la deducción (KRIELE, 1976: 143; BRAUN, 2016: 170). En el ámbito jurídico es una técnica que estimula la intuición (BOKELOH, 1973: 27), buscando soluciones sin apoyarse en la deducción a partir de un sistema (MÖLLERS, 2019: 495). La tópica, tal y como se desarrolló históricamente y también por Viehweg, no se presenta como un modo de operacionalizar el Derecho positivo. Parece estar al margen precisamente del material jurídico. Por esa razón, la tópica permite abrir un debate sobre las pre- 
misas sobre las que se asienta el propio sistema (SEIBERT, 1973: 52); pero no parece idónea para trabajar en el marco de un Derecho dado. La búsqueda de las premisas a partir de las cuales debe desarrollarse la argumentación se presenta, de este modo, como una tarea muy compleja que requiere de una racionalización anterior (LAUNHARDT, 2010: 17), puesto que no parece haber un mapa previo de argumentos. Para simplificar el proceso, se proponen precisamente lugares comunes a los que se puede reconducir la búsqueda de una solución. Aristóteles ordenaba esos tópicos en torno a las siguientes categorías: accidente, género, lo propio y definición (ARISTÓTELES, 2011: 327 ss.).

38. Esta tópica parece ser la verdadera para Viehweg. Comparte, así, con Cicerón, la concepción de la tópica como un procedimiento de búsqueda de premisas que ayudan a desarrollar verdades indiscutibles (CICERÓN, 1997: 222; VIEHWEG, 2007: 67). Viehweg señala que la selección de las premisas se hace a modo de ensayo, de forma arbitraria, aunque buscando "premisas objetivamente adecuadas" (VIEHWEG, 2007: 60). El problema está en determinar cuándo las premisas son objetivamente adecuadas. Para ello habría que acudir al consenso, al sentido común o la aceptación, como el modo de establecer la corrección de la solución a un problema (CANNARIS, 1983: 140) -aunque ese consenso no siempre sea habitual en la práctica (BÖCKENFÖRDE, 1976: 2094)-.

39. La utilización de lugares comunes demuestra que la tópica no renuncia a la abstracción como herramienta del pensamiento. Esto la acerca a otros métodos jurídicos, como el sistemático conceptual, que se apoya en la creación de conceptos que ayudan a ordenar y explicar todo el Derecho [ $\$ 55$ ss.]. Pero entonces se plantea la pregunta por determinar qué caracteriza a la tópica frente a otras aproximaciones al estudio y práctica del Derecho. En este sentido, la tópica no parte de la deducción en el marco de un sistema ni de la inducción del material jurídico. Por supuesto, atiende a las circunstancias del caso y del problema planteado para buscar una solución, pero esa búsqueda se realiza a través de tópicos aceptados por la comunidad. La importancia del proceso de creatividad -que se destaca en la selección de premisas- y el apoyo en lo que es aceptable en una comunidad dada -sin partir de proposiciones jurídicas prestablecidas-, serían dos de las principales características que diferencian a la tópica de otras aproximaciones metodológicas.

40. Larenz caracteriza a la tópica de Viehweg como un "procedimiento especial de discusión de problemas" (VIEHWEG, 2007: 29), que usa puntos de vista, planteamientos y argumentos generales aceptados como estables que pueden emplearse a favor y en contra de una decisión. No hay en ningún momento un interés por aprehender y hacer una conexión comprensiva con un sistema (LARENZ, 2001: 153). Pero sí hay un interés por conectar el problema con puntos de vista que se han obtenido mediante procedimientos previos de abstracción. El punto de partida es, por tanto, una opinión acreditada, de la que después se pueden extraer conclusiones. No hay, por tanto, una creación o invención totalmente libre; está ligada al problema planteado. Es más, para tratar de hacer compatible la tópica con el Derecho positivo y el material jurídico, esa creación es posible siempre que sea conforme a las normas 
o a los precedentes que se consideran relevantes (ZIPPELIUS, 1967: 2232; BOKELOH, 1973: 40). Ello no obsta, por supuesto, a que las premisas puedan buscarse también en otras disciplinas siempre que se respete el Derecho vigente (BOKELOH, 1973: 27), lo que permitiría la introducción de una aproximación multidisciplinar en el Derecho.

41. Si se enfoca de este modo, la tópica puede llegar a cumplir una función instrumental en el Derecho contemporáneo. No puede justificar por sí sola la solución de un problema jurídico al margen del Derecho positivo (ZIPPELIUS, 1967: 2233; BOKELOH, 1973: 7). Pero la tópica y sus herramientas, los tópicos, pueden cumplir una función eminentemente heurística, de búsqueda de soluciones jurídicas a través de la buisqueda de puntos de vista que permitan articular la discusión en los casos en que deban formularse nuevas soluciones jurídicas no previstas en el ordenamiento jurídico (WEINBERGER, 1973: 22; BOKELOH, 1973: 27; MÖLLERS, 2019: 495). Además, la tópica puede llegar a cumplir también una función prescriptiva, en la medida en que pretende que las soluciones alcanzadas sirvan verdaderamente para resolver conflictos y, por tanto, orientar conductas. Esa función está estrechamente vinculada a su finalidad de persuasión (COFRÉ LAGOS, 2002: 29).

42. En negativo, la tópica y los tópicos no tienen una finalidad ordenadora, clasificatoria o explicativa, como sí sucede con las abstracciones conceptuales ordenadas en sistemas más o menos cerrados; tampoco se orientan una demostración guiada por las reglas de la lógica (WEINBERGER, 1973: 23). La tópica busca estar cerca del problema para encontrar una solución. En ese sentido, puede considerarse que la tópica tiene una vertiente productiva (ZIPPELIUS, 1967: 2232).

\section{4. Ámbito de aplicación}

43. En el planteamiento de la tópica que se formula por Viehweg no hay espacio, o un espacio claro, para el Derecho positivo. La tópica se centra en la necesidad de adaptar continuamente el Derecho a los problemas de la realidad conforme a la opinio iuris (BOKELOH, 1973: 77, 83; GARCÍA AMADO, 2019). Uno de los problemas que plantea la fundamentación de la tópica de Viehweg en la tópica antigua y medieval es la diferencia fundamental de contexto, que le lleva a obviar la importancia de racionalizar el trabajo con el material jurídico (Rechtsstoff). Se refiere a momentos en los que no había un centro de poder ni, por tanto, un Derecho positivo formalizado. Y no hace un esfuerzo por adaptar las premisas de esa configuración de la tópica a las exigencias del Estado de Derecho contemporáneo. En este sentido, se ha visto cómo los tópicos formales y materiales [ $\$ \$ 33$ ss.], que surgieron en distintos momentos históricos, tienen un encaje muy diferente en el Derecho actual.

44. Para Viehweg un problema es toda aquella pregunta que hay que resolver y en la que cabe más de una respuesta (VIEHWEG, 2007: 59). Lo identifica con la aporía, que es un problema que no tiene una respuesta definitiva $(\mathrm{BOKELOH}$, 1973: 58). Al respecto, se ha señalado que, en la medida en que el jurista está vincu- 
lado a la Ley, no queda espacio para la tópica (DIEDERICHSEN, 1966: 703). Pareciera, así, que la Ley puede y quiere programar todas las conductas del poder público y de los particulares; considerando una patología los casos de existencia de lagunas jurídicas. Sin embargo, es claro que en el Derecho existen -y es necesario que existanámbitos de discrecionalidad, donde la toma de decisiones no está programada y debe integrarse por quien es responsable de la decisión. En ese ámbito es posible ubicar a la tópica contemporánea, sin que se plantee un problema de compatibilidad con las normas jurídicas existentes (SCHRÖDER, 2012: 80); puesto que la tópica jurídica, como cualquier otra aproximación metodológica aplicativa, debe respetar en todo caso el Derecho vigente. En este sentido, Cannaris reconocía que la tópica podía jugar un papel alli donde no se hayan concretado suficientemente valores juridico-positivos y sea preciso dotar de contenido a las normas (CANNARIS, 1983: 149); y Böckenförde apuntaba que la tópica podía ser un método adecuado de interpretación constitucional, debido, precisamente, a la imprecisión y amplitud de los principios constitucionales (BÖCKENFÖRDE, 1976: 2092; también, ESSER, 1990: 50).

45. En ese plano, se eliminan los problemas de vinculación a la Ley, que queda garantizada siempre que se respeten los mandatos normativos que dirijan la toma de la decisión. Esto implica que las normas jurídicas no pueden considerarse tópicos que entran a formar parte de la argumentación jurídica como meros puntos de vista que pueden ayudar a solucionar un problema (sobre ese peligro, BÖCKENFÖRDE, 1976: 2092). Las normas deben primar por encima de los posibles tópicos que se aduzcan para la solución del problema. La argumentación tópica tiene, así, como límite la vinculación al Derecho positivo (MÖLLERS, 2019: 496), que es el fundamento del Estado de Derecho. Cuando la subsunción en una norma permite resolver un problema, no hay espacio para la tópica (BOKELOH, 1973: 122). No obstante, hay que tener en cuenta que, en algunos casos, exigencias de justicia llevaron a primar una solución tópica sobre una solución aplicada en la subsunción de las normas vigentes: es el caso paradigmático de la confianza legítima. Esos supuestos deben considerarse excepcionales y exigen una fuerte carga justificativa de la introducción de una solución al margen del Derecho vigente. Además, su éxito en la justificación de las decisiones lleva normalmente a incluirlos en el propio Derecho. La tópica conduce de este modo a la creación de Derecho positivo. Sobre esta cuestión se vuelve un poco después $[\$ \$ 53$ ss.].

\subsection{Valor metodológico}

46. Un primer filtro de la dimensión metodológica de la tópica permite afirmar que en la tópica -particularmente referida al trabajo con tópicos (tópica de segundo grado)- parece haber una descripción suficiente de un modo de proceder, aunque, sin duda, mucho más abierto que el método conceptual (en la tópica de primer grado es más difícil encontrar un proceso intelectual suficientemente pautado, ya que se sitúa en un momento del pensamiento creativo). Al apoyarse en la argumentación en torno a lugares comunes, parece que no hay suficiente control, pero hay reglas que permiten 
determinar cuál es la mejor argumentación. Por esa razón, parece indiscutible -sin entrar todavía a la concreta caracterización como método-, que la tópica tiene valor metodológico. Lo ha tenido históricamente y hay que determinar si puede tener alguna virtualidad en este plano en la actualidad. A continuación, se trata de discernir cuál es, en su caso, esa dimensión metodológica de la tópica en el Derecho público contemporáneo.

\subsection{1. ¿La tópica como método en la actualidad?}

47. Se ha señalado anteriormente que la negación del carácter de método de la tópica estaba vinculado al reconocimiento del método axiomático como el único posible y, al mismo tiempo, imposible de materializar [supra $\$ \$ 24$ ss.]. Ese planteamiento se critica por su extremo formalismo y por su caricaturización de la idea de sistema deductivo (GARCÍA AMADO, 2019). En la misma línea, se señala que, en la medida en que los catálogos de tópicos era sistemas rudimentarios, volver del sistema a la tópica supondría una involución (BOKELOH, 1973: 15; KRIELE, 1976: 145). Asimismo, se afirma que la tópica es un estadio previo a la elaboración del pensamiento jurídico (CANARIS, 1995: 160).

48. En la actualidad, la idea de sistema se corresponde más con una forma de pensamiento que aspira a la unidad y al orden que con un sistema lógico-formal cerrado (HILBERT, 2015: 4); lo que se corresponde con la concepción de la Parte General del Derecho administrativo como una idea ordenadora de carácter flexible (SCHMIDT-ASSMANN, 2003: 2-3). Parece necesario desprenderse de esa imagen rigida de método para realizar un análisis más amplio sobre la posible consideración de método de la tópica. Es más, cabe añadir que muchos de los métodos jurídicos aceptados comúnmente como tales -Derecho comparado (al que se ha caracterizado como tópico: KRAMER, 1969: 5 ss.; VELASCO, 2019), análisis económico del Derecho (DOMÉNECH, 2014) o análisis empírico, por ejemplo- podrían tener dificultades para seguir siendo considerados de esa manera si se les exigieran las características propias del método lógico-deductivo basado en un sistema axiomático.

49. Así pues, para analizar si la tópica puede considerarse un método hoy, hay que determinar en primer lugar una definición de método. En ese sentido, puede convenirse en que en el ámbito jurídico un método se refiere a formas "ordenadas, disciplinadas y controlables de proceder para formular proposiciones jurídicas correctas a partir de las normas que integran el ordenamiento jurídico" (RODRÍGUEZ DE SANTIAGO, 2002: 1282); o a una "forma rigurosa de proceder para llegar a un resultado que pueda presentarse como racional y, por tanto, intersubjetivamente controlable" (RODRÍGUEZ DE SANTIAGO, 2016: 11). El Estado de Derecho exige que exista una posible verificación racional de la elaboración científica del Derecho; al igual que sucede con la racionalización de la información en la práctica jurídica (HORN, 1967: 601, 605; ATIENZA, 1999: 38). Hay que determinar si la tópica es capaz de satisfacer estas exigencias de racionalidad y de control intersubjetivo. 
50. Al respecto, se ha entendido tradicionalmente que las formas de pensamiento distintas del iusnaturalismo racionalista no satisfacen las exigencias de racionalidad propias de cualquier método (HORN, 1967: 604; GARCÍA AMADO, 1999: 131). Sin embargo, el proceso de razonamiento dialéctico puede interpretarse como una forma de elaboración de conocimiento mediante el razonamiento práctico, junto al descubrimiento y la demostración (AARNIO, 1979: 20; PERELMAN, 1980: 129). En esa clave, la tópica centrada en la aplicación de tópicos podría situarse en el ámbito de la denominada "lógica de lo razonable" (HORN, 1967: 604; MANSON, 1977: 197; PERELMAN, 1980: 59). Es un tipo de argumentación material que tiene un importante componente intersubjetivo (ATIENZA, 1999: 42; GARCÍA AMADO, 1999: 137) y que conecta con la razonabilidad de los puntos de vista aportados y de las soluciones propuestas a partir de su convicción de un auditorio universal (GARCÍA AMADO, 1999: 141; de forma crítica, NIETO, 2007: 212213). En esa línea, la tópica contribuye a la justificación externa de las decisiones (ATIENZA, 2013: 31, 104). La argumentación jurídica está plagada de ideas que no son controlables lógicamente, pero cumplen funciones importantes desde el punto de vista tópico (por ejemplo, la relevancia de un argumento o su aceptabilidad). Además, la tópica solo alude a la necesidad del consenso para confirmar la utilización de puntos de vista en la solución de ciertos problemas, en los que el Derecho ha abierto un margen de decisión. La aceptación de los lugares comunes ayuda a racionalizar esa tarea de invención que dará pie a la aplicación de reglas lógicas.

51. En ese sentido, hay que añadir que la tópica no renuncia a las exigencias lógicas en el desarrollo de silogismos. Una vez establecidas las proposiciones opinables, las premisas, hay que razonar evitando contradicciones con el fin de lograr conclusiones aceptables (VIEHWEG, 2007: 40). En ambos casos, hay que tener en cuenta que se trata de formas de pensamiento asociativo, esto es, que tratan de conectar con lo que ya se conoce (ZIPPELIUS, 1967: 2232). La diferencia puede estar en su finalidad: en la tópica, se trata de resolver problemas, mientras que con el sistema se busca, fundamentalmente, contribuir a la construcción y perfeccionamiento del propio sistema. Esto explica que la forma de operacionalizar intelectualmente el Derecho no sea muy diferente en ninguno de los dos casos. La tópica también acude a los silogismos y las inducciones. La diferencia estribaría, para los defensores de la tópica, en la distancia que hay entre la realidad y el pensamiento jurídico. En el sistema hay una gran distancia, que debe salvarse a través de largas cadenas deductivas, que van de los conceptos y las proposiciones del sistema al problema. Sin embargo, en la tópica, el pensamiento no se eleva tanto sobre el problema. Lo que hace que las posibles cadenas deductivas nunca tengan una gran longitud (VIEHWEG, 2007: 59).

52. A la vista de estas apreciaciones puede considerarse, por tanto, que la tópica es un método o, al menos, que tiene valor metodológico en el Derecho. Por supuesto, tiene muchas limitaciones: no ayuda a seleccionar qué decisión, de todas las propuestas, es la más racional; lo que la diferencia del sistema (GARCÍA AMADO, 1999: 138; RODRÍGUEZ DE SANTIAGO, 2002: 1289). Pero, a través de la buisqueda de lugares comunes, aceptados por la comunidad jurídica, ayuda a racionalizar la selección 
de las premisas que servirán de base para resolver un problema jurídico. La operacionalización posterior de esas premisas se llevará a cabo de forma lógica, de acuerdo con los silogismos que acompañan habitualmente la aplicación del Derecho. Ciertamente, se trata de una aproximación limitada, por cuanto no ofrece criterios para seleccionar unos tópicos frente a otros (GARCÍA AMADO, 1999: 138). Sin embargo, la negación de su consideración de método dejaría fuera del análisis metodológico un enfoque que puede aportar explicaciones útiles en el tratamiento académico y aplicativo del Derecho.

\subsubsection{La tópica en la creación de Derecho positivo}

53. El valor metodológico contemporáneo de la tópica debe ponerse en conexión con su valor metodológico en el pasado. En el periodo medieval el Derecho cristalizó en catálogos de tópicos y de reglas jurídicas siguiendo el modelo de los libros de reglas romanos y, en especial, del catálogo de reglas del Digesto (DOMINGO, 2003: 19). Este proceso permitió una elaboración conceptual posterior más o menos sistemática que desembocó en la formación de normas de Derecho positivo. Los tópicos han sido, así, fundamentales en la formación del Derecho occidental (COFRÉ LAGOS, 2002: 40). Hay que tener en cuenta que el legislador bebe de las mismas fuentes de conceptos e ideas que el resto de operadores jurídicos, de modo que los tópicos constituyeron un yacimiento fundamental para acuñar las soluciones jurídicas incorporadas al Derecho positivo (BRAUN, 2016: 172). Muestra de ello es que históricamente la búsqueda del Derecho se realizó con base en la tópica, a ciegas, para después convertir las conclusiones en fuentes del Derecho (VIEHWEG, 2007: 89). Por eso es posible encontrar un vínculo del Derecho positivo actual con máximas jurídicas o aforismos antiguos, que se elaboraron en el marco de la tradición tópica. Viehweg alude a este fenómeno señalando que los tópicos pueden ganar importancia y abrirse camino en la legislación (VIEHWEG, 2007: 149).

El caso más claro de incorporación de tópicos al Derecho positivo es el del análisis de la admisi-
bilidad de un recurso, mediante los requisitos de la legitimación (estado), plazo (tiempo), com-
petencia territorial (lugar), etc. (ZIPPELIUS, 1967: 2231). También hay principios que se crean
a partir de la tópica. Es el caso del principio de protección de la confianza que se puede enraizar
con la buena fe y la culpa in contrahendo que, a su vez, se emparenta con la máxima venire contra
factum proprium non valet (BOKELOH, 1973: 28). En la misma línea, hay que tener en cuenta
que el argumento a simile (SCHRÖDER, 2012: 126 ss.) ha conducido a la exigencia de igualdad
en la aplicación de la Ley. Otros ejemplos podrían ser el tópico de prior in tempore potior in iure,
que ha pasado a ser un principio de prioridad y el de Hand wahre Hand, que se consagra en el
principio de buena fe (DIEDERICHSEN, 1966: 703).

54. En estos casos, los tópicos pasan a tener la vinculatoriedad propia del Derecho positivo porque ya no se explican por su condición tópica, sino por su naturaleza jurídica. No obstante, su origen tópico puede dificultar en ocasiones su sistematización con reglas de ordenación jerárquica y vinculatoriedad total. Así, por ejemplo, en el caso de los cánones de interpretación de las normas o en las reglas de resolución de conflictos normativos es difícil encontrar una prelación clara entre las reglas 
existentes (RODRÍGUEZ DE SANTIAGO, 2016: 70 ss.). La fuerza persuasiva del argumento parece pesar más en estos casos que su valor dentro de un sistema cerrado. Lo mismo sucede con los aforismos o máximas jurídicas medievales que han llegado a nuestros días y que dificultan su integración en un contexto sistemático, así como su aplicación racionalizada cuando se aplican de forma simultánea a las reglas de Derecho positivo a las que han dado lugar (como ejemplo, sirva la doctrina de los actos propios en el Derecho público, DÍEZ, 2018b: 64-65).

\subsubsection{La tópica en la ordenación del Derecho}

55. Junto a la importante contribución de la tradición tópica a la creación de Derecho, hay que destacar su papel en la ordenación del Derecho. Aunque pueda parecer contradictorio, la tópica o, en sentido más amplio, la tradición tópica occidental, ha jugado un papel fundamental en el desarrollo de herramientas de ordenación del Derecho, que, en última instancia, se perfeccionaron a través de la dogmática jurídica y del pensamiento sistemático. La tópica antigua, griega y romana, ocupaba un espacio muy amplio en la ordenación del pensamiento. Cuando Cicerón describe la forma de proceder con base en la tópica, enumera las siguientes herramientas (CICERÓN, 1997: 222 ss.): a) silogismos e inducción; b) descubrimiento y captura de premisas; c) diferenciación de las denominaciones y de las categorías; d) diferenciación de los géneros y tipos; y e) analogías y semejanzas entre distintos géneros. Si se analizan estas actividades del pensamiento en la actualidad, se pondrían en relación con la construcción del pensamiento a través de conceptos ordenados en un sistema más o menos cerrado y no con la tópica moderna -de hecho, Cicerón dedica una buena parte de su tópica a las definiciones (CICERÓN, 2017: 5 ss.)-.

56. Con la salvedad del descubrimiento y la captura de premisas, las demás herramientas de la tópica han conducido a la ordenación de la realidad con base en categorias, géneros y tipos, a los que se han atribuido distintas denominaciones. Esa operación se realiza por inducción y deducción, teniendo en cuenta las semejanzas y diferencias entre los distintos conceptos creados. Esas herramientas conforman, en gran parte, las técnicas de ordenación sistemática del Derecho que se perfeccionaron en el siglo XIX. Esto es así, porque desde la Edad Media la tópica se movió en un doble plano, como parte de la lógica y como parte del arte de la invención (SCHRÖDER, 2012: 27-28). La dialéctica escolástica se puso al servicio de la ordenación del Derecho, lo que cristalizó en la comprensión actual de los sistemas jurídicos (BERMAN, 2001: 154 ss.).

57. Algo similar sucede en relación con los catálogos de tópicos y máximas jurídicas medievales. Aunque se renunciaba a su ordenación mediante criterios lógicos -de hecho, se solían ordenar alfabéticamente (DIEDERICHSEN, 1966: 697; un ejemplo actual en PEREIRA-MENAUT, 2001: passim)-, han suministrado un yacimiento de soluciones jurídicas con un grado bajo o medio de abstracción, a partir del cual se han podido realizar inducciones para la creación de conceptos, principios o la 
formalización de instituciones. Los catálogos de tópicos nutrieron, de este modo, al sistema deductivo (BERUMEN, 2015: 536). En tiempos del humanismo jurídico, se comienza a ir de lo general a lo particular, así como de las definiciones con el fin de acabar con un Derecho caótico. En ese contexto, los lugares comunes comenzaron a servir para ordenar el Derecho común. Dejaron de ser herramientas de argumentación y pasaron a ordenar el material jurídico romanista a partir de instituciones jurídicas (RODRÍGUEZ PUERTO, 2001: 366-367). Por su parte, los catálogos de tópicos actuaban como sistemas rudimentarios, que buscaban ordenar un material caótico para hacerlo aprehensible (BOKELOH, 1973: 15; KRIELE, 1976: 145). Su ordenación con criterios axiológicos, objetivos o lógicos, constituyó un paso previo a su sistematización (ZIPPELIUS, 1967: 2233). Ahora bien, no será hasta la Modernidad cuando se aspire a reconducir el material jurídico a un único principio o institución (RODRÍGUEZ PUERTO, 2001: 368).

58. En la tópica contemporánea se suele aludir a la falta de criterio ordenador de los catálogos de tópicos y a la inexistencia de relación jerárquica entre ellos. Sin embargo, el propio Viehweg seńala que no cualquier tópico es adecuado para cualquier discusión. Para discernir cuáles lo son hay que hacer un "cuadro de conjunto" de posibles debates preguntando qué fuentes de pruebas se adecuan a cada uno. El propio Aristóteles organizaba la tópica por zonas de problemas (VIEHWEG, 2007: 50-55). Esta creación de cuadro de conjunto parece asimilable a la creación de tipos que permitan establecer grupos de casos en función de los problemas que se plantean (DÍEZ, 2018a: $\$ \$ 187$ ss.). La operacionalización de los tópicos conlleva, por tanto, un proceso de abstracción. No se trata solo del trabajo sobre el problema concreto. En el momento en que hay que buscar soluciones jurídicas, tiene lugar un proceso de cotejo de la realidad y el Derecho. En esta misma línea, se considera que los tópicos pueden elaborarse para crear nuevos conceptos jurídicos o un nuevo instituto jurídico (MÖLLERS, 2019: 497) o un principio dogmático, en el que no se pueden subsumir supuestos de hecho porque es demasiado indeterminado (KRIELE, 1976: 118, 151).

59. Con base en este análisis puede afirmarse entonces que, históricamente, no existe una cesura clara entre tradición tópica y sistemática; ni tampoco una diferencia tan grande con respecto a las herramientas intelectuales utilizadas en cada una de ellas (que se reconducen a la abstracción). La principal diferencia está en que la tópica contemporánea patrocinada por Viehweg destaca la distancia existente entre sistema y práctica. Por ello, considera que la incardinación de los catálogos de tópicos en un sistema deductivo altera la función de los tópicos, alejándolos del problema (VIEHWEG, 2007: 66); y pone de manifiesto las disfunciones que se generan al poner la realidad al servicio del sistema. Pero esa distancia no se deriva únicamente de la conversión de los catálogos de tópicos en un sistema. El monopolio del Estado en la producción del Derecho y el encumbramiento de la ley general y abstracta como garantía máxima de justicia han contribuido -en el Derecho continental- a crear estructuras jurídicas (normativas, organizativas y procedimentales) que muchas veces se alejan de los problemas de la realidad. En la pregunta por la justicia, el Derecho continental dejó de lado la justicia del caso concreto con el protagonismo del juez, 
en favor de una justicia de soluciones generales expresadas en las leyes (SCHAUER, 2004: 199). Por esa razón, en nuestros sistemas parece que el espacio para la tópica es, necesariamente, más reducido que en otros sistemas como el common law.

\section{TÓPICA JURÍDICA Y DERECHO PÚBLICO}

60. Tras la caracterización de la tópica y los tópicos en la actualidad, es momento de abordar la conexión entre tópica y Derecho público. La tópica jurídica se desarrolló en un momento histórico en el que el Derecho público aún no se había formalizado como tal en su forma actual. Es más, el Derecho público se elabora durante el predominio del método jurídico clásico, de construcción lógico-sistemática, tomando como referencia el Derecho privado (DÍEZ, 2018a: $\$ \$ 115$ ss.). Esto significa que la tópica no jugó, en principio, un papel protagonista en el Derecho público, ni tampoco con posterioridad, después de la obra de Viehweg. La obra de los autores que se ocuparon del tema, especialmente en la década de los sesenta del siglo pasado, se centró en ejemplos provenientes del Derecho privado. Solo en algún caso excepcional, se hizo un esfuerzo por discernir qué papel podría jugar la tópica en el Derecho constitucional, al hilo de las teorías de la interpretación constitucional (un buen ejemplo en BÖCKENFÖRDE, 1976).

61. En este escenario, una vez realizada una caracterización contemporánea de la tópica jurídica, hay que tratar de identificar qué aporta, en su caso, la tópica al Derecho público continental actual. Dicho de otro modo, se pretende determinar qué ayuda a explicar mejor o a hacer en el ámbito jurídico la tradición de la tópica. En ese sentido, se propone entender que la tópica contribuye a explicar, al menos, los siguientes fenómenos: la función tópica de algunos conceptos jurídicos; las técnicas tópicas de resolución de problemas ligadas a esos conceptos; y la utilización de aforismos en el Derecho público y el recurso en la argumentación a lugares comunes. Los dos primeros se referirían a la utilización de tópicos formales, con una función propia de la tópica clásica. El tercero hace alusión, sin embargo, a la utilización de tópicos materiales, cuya función es más parecida a la de las reglas jurídicas que a la de los tópicos, entendidos como puntos de vista o lugares comunes que ayudan a buscar soluciones a los problemas jurídicos [al respecto, supra $\$ \$ 34$ ss.].

\subsection{La función tópica de los conceptos jurídicos}

62. Se ha señalado anteriormente que la tópica suele percibirse como una técnica o método que se opone al pensamiento sistemático que se centra en la elaboración conceptual del Derecho [ $\$ \$ 16$ ss.]. Ahora bien, más allá de la compatibilidad teórica de ambas aproximaciones, parece posible encontrar un punto de conexión entre la tradición del método jurídico clásico, de creación sistemática conceptual, y la tradición tópica. Ese punto de conexión sería la identificación de una función tópica de los conceptos jurídicos (HORN, 1967: 606). La tópica, como método 
jurídico, está orientada a la solución de problemas mediante una discusión apoyada en lugares comunes que gozan de aceptación en la comunidad jurídica. Esa discusión se canaliza a través de los tópicos formales a los que se ha aludido más arriba $[\$ \$ 33$ ss.]. Esos tópicos formales son, en muchas ocasiones, conceptos que entran a formar parte del universo jurídico. Por esa razón, su virtualidad puede explicarse desde una perspectiva distinta a la de la tópica, la conceptual. El resultado de ese proceso es la integración entre el pensamiento conceptual y el pensamiento tópico porque hay conceptos jurídicos que cumplen una función tópica. Por supuesto, para aceptar esta propuesta, hay que concebir a los conceptos como herramientas útiles para el pensamiento jurídico más allá de su caracterización como piezas incardinadas en un sistema lógico-deductivo y hay que admitir la pluralidad de formas de los conceptos jurídicos con funciones muy diversas, más allá de la clásica ordenación y clasificación del material jurídico (instituciones, conceptos clasificatorios, tipos, principios, conceptos clave, conceptos puente e iconos jurídicos, entre otros; al respecto, DİEZ, 2018a: 108 ss.). Asimismo, hay que centrarse en la naturaleza conceptual de algunos tópicos formales.

63. Los conceptos que cumplen una función tópica tienen de particular que no se crean mediante inducción a partir de las normas, ni se deducen a partir de otros conceptos. Se crean a partir del problema para permitir su análisis y la búsqueda de una solución. Esto no significa, a priori, que su grado de abstracción sea menor. Pueden ser conceptos abstractos -de hecho, en la práctica lo son-, pero han de estar caracterizados por la orientación hacia la resolución de problemas. No son conceptos que contengan una solución; sino que ofrecen un punto de vista con el que buscar una solución mediante el análisis del caso y el cruce de argumentos. Por esa razón, este tipo de conceptos se ha creado normalmente en sede jurisdiccional. Y, en muchos casos, se han elaborado en un contexto de constatación de los límites del Derecho positivo en la respuesta a problemas jurídicos especialmente complejos -véase, por ejemplo, la caracterización de la confianza legítima como el caballo de Troya del Estado de Derecho (OSSENBÜHL, 1972: 29)-. De hecho, podría decirse que algunas de las elaboraciones conceptuales más importantes del Derecho público contemporáneo tienen este carácter tópico.

64. En esta clave, un ejemplo de concepto con función tópica podría ser el principio de proporcionalidad con sus elementos: idoneidad, necesidad y proporcionalidad en sentido estricto. Estos conceptos que tienen la virtualidad de permitir analizar los problemas que se plantean sin predefinir una solución concreta. Son tópicos en el sentido aristotélico, fomentan la discusión, obligan a la justificación de la decisión y orientan en la búsqueda de una solución que pueda ser finalmente aceptada porque persuada, en este caso, desde el punto de vista jurídico. También el principio de protección de la confianza -que se ha considerado como un tópico (KRIELE, 1976: 147)- podría considerarse un concepto con función tópica, que ayuda a resolver problemas concretos a partir de un concepto: la confianza digna de protección. Al concepto de precedente también podría atribuírsele una función tópica. En esta misma línea, en el Derecho administrativo se ha señalado que el concepto 
de orden público es un tópico fundamental (BOKELOH, 1973: 125). Por último, cabría entender que el concepto de eficiencia que se emplea en el análisis económico del Derecho también es un concepto con una función tópica.

65. Estos conceptos no tienen una intensión propia de los conceptos clasificatorios que permite una aplicación dicotómica (como, por ejemplo: válido-inválido): son más vagos y se sitúan en un punto medio-alto de la escala de abstracción. Además, la forma de aplicarlos no es la subsunción, tal y como se entiende en el marco de los conceptos desarrollados por la dogmática jurídica. Son ideas que ayudan a abrir la discusión, a buscar distintos puntos de vista y a argumentar para justificar la decisión final que resuelva el problema planteado. En estos casos se ha llegado a hablar de "conceptos guía" (COFRÉ LAGOS, 2002: 39). Por esa razón, es habitual que se articulen entre sí o que se agrupen a través de tests o técnicas -como se desarrolla más adelante $[\$ \$ 67$ ss.]-. Por supuesto, el margen de invención al que se refiere la tópica es estrecho en el caso de estos conceptos. Existe un universo normativo y jurídico al que hay que hacer referencia, precisamente, si se quiere lograr la aceptación de la solución; lo que reduce el margen de creación. Pero ello no quita importancia al hecho de que estos conceptos se puedan incardinar de forma más clara en el marco de la tradición tópica que en el de la elaboración de conceptos propia de una concepción lógico-formal del Derecho.

66. En cuanto a la forma en que se presentan estos conceptos, hay que señalar que suelen aparecer habitualmente como principios. La abstracción de su intensión y la ausencia de una aplicación subsuntiva es coherente con esta configuración habitual como principios, tanto en la jurisprudencia, como en su positivización posterior en las normas jurídicas. Sin embargo, hay que tener en cuenta que -sin perjuicio de que estos conceptos también puedan tener, en su caso, una dimensión principial- no actúan como máximas de optimización cuando se proyectan sobre problemas jurídicos concretos. Tampoco surgen de forma natural (de forma crítica, GARCÍA AMADO, 2011: 61), sino del consenso de la comunidad jurídica a partir de los problemas que se deben resolver. La consideración de estos conceptos como principios parece estar orientada a reforzar su incorporación en el sistema jurídico, dignificando su posición y justificando su inclusión en el Derecho positivo - por ejemplo, cuando el principio de proporcionalidad se considera una emanación de la cláusula de Estado de Derecho o cuando se vincula el principio de protección de la confianza con el principio de buena fe y la construcción de la culpa in contrahendo de Jhering-.

67. Por otro lado, también se ha llegado a identificar la función tópica con la heurística, que caracteriza, fundamentalmente, a los denominados conceptos clave y los conceptos puente (BRAUN, 2016: 172; DÍEZ, 2018a: 205 ss.). Sin embargo, la heurística abre nuevos ámbitos de investigación, identifica nuevas realidades y dirige la atención a nuevos problemas; mientras que la tópica se sitúa en una dimensión cetética: parte de un problema o grupo de problemas ya identificados y procura trazar un eje de análisis y discusión de la solución que debe brindarse en cada caso. En este punto, hay que tener en cuenta que la acepción del concepto de tópico, entendido simplemente como una idea extendida y aceptada en la comunidad, puede ser confuso en 
la medida en que se refiere a ideas basilares en nuestras sociedades que, prácticamente tienen un valor institucional y a las que se puede atribuir la condición de concepto clave: principio democrático, Estado de Derecho, etc. (BRAUN, 2016: 172). Las funciones, sin embargo, parecen ser distintas y tienden a proyectarse en planos metodológicos diferentes: la función heurística es más propia de la metodología académica, mientras que la función tópica se correspondería con una metodología aplicativa.

En el ámbito académico, un ejemplo de concepto elaborado de manera muy apegada al problema es, a mi juicio, el de la Administración de la escasez (ARROYO y UTRILLA, 2015). Consigue poner el acento en un elemento común a numerosos problemas que se plantean en la práctica, con el fin de racionalizar las soluciones dadas en esos casos y poder llevar a cabo, en su caso, planteamientos analógicos. Al mismo tiempo puede considerarse un concepto clave, con una función heurística, en la medida en que la escasez parece estar llamado a ser uno de los conceptos más importantes en nuestras sociedades acechadas por los efectos del cambio climático y de las transformaciones sociales que traerán aparejados.

\subsection{Las técnicas tópicas de solución de problemas jurídicos}

68. Estrechamente vinculada a la función tópica de los conceptos jurídicos -que se sitúa principalmente en un plano académico- podría identificarse una segunda manifestación de la tópica en el Derecho público: las técnicas tópicas de solución de problemas jurídicos, que se utilizan en un plano metodológico aplicativo. Los conceptos con función tópica suelen agruparse o articularse en tests o técnicas que permiten resolver un problema. Así, por ejemplo, el principio de proporcionalidad se articula en un triple test (BARNES, 1998); del mismo modo que la propia técnica de la ponderación en la toma de decisiones conformadoras -no en el ámbito de los derechos fundamentales (al respecto, GARCÍA AMADO, 2009: 1-42)-, que no se adscribe a la tradición lógica, sino a la tópica (BERUMEN, 2015: 533). Algo similar podría llegar a afirmarse en relación con la técnica de evaluación de costes y beneficios en el análisis económico del Derecho (DOMÉNECH, 2014: 101 ss.).

La ponderación permite establecer reglas de prevalencia condicionada de cada principio (RODRÍGUEZ DE SANTIAGO, 2016: 137) y reconducir muchos de los problemas de justicia que se plantean en el Derecho (ZIPPELIUS, 1967: 2233). Los criterios que permiten establecer esas reglas se han caracterizado como tópicos que connotan a los principios para condicionar su prevalencia (BERUMEN, 2015: 542). La ponderación se apoya en conceptos que tienen una función tópica: interés y proporcionalidad, fundamentalmente. De hecho, las críticas que se realizan a la ponderación coinciden con las críticas que se formulan habitualmente a la tópica: imprevisibilidad de sus resultados, justicia de caso concreto, atribución de poder a quien toma la decisión, entre otras (al respecto, en detalle, RODRÍGUEZ DE SANTIAGO, 2000: 12, 143, y 2016: 139 ss.). En ese sentido, puede entenderse como una técnica de carácter tópico; aunque se ha teorizado como un método de aplicación de un tipo de normas y de conceptos: los principios. La identificación de su carácter tópico permite, sin embargo, apelar a la orientación al problema y a la razonabilidad de las decisiones que se tomen en el marco de la ponderación.

69. En esos casos, varios conceptos con función tópica se ordenan para analizar y encontrar una solución a un problema determinado. Esos conceptos no suelen estar positivizados, ni derivan del Derecho positivo; de modo que son esos, pero podrían 
ser otros. En ese sentido, son lugares comunes o tópicos en sentido estricto, porque no se trata de un catálogo cerrado, sino flexible, y porque no derivan de un proceso deductivo en el marco de un sistema. La comunidad jurídica acepta que se apliquen tal y como se determina en la jurisprudencia. Aunque, al mismo tiempo, pueden llegar a alcanzar carácter vinculante -y pasar a ser Derecho- a través de su fijación en las decisiones de los Altos Tribunales.

70. Esta forma de agrupación de conceptos con función tópica a través de lo que aquí se han denominado técnicas tópicas supone un avance con respecto a los catálogos de tópicos que se manejaban en la Antigüedad y en la Edad Media. La comprensión actual del Derecho impediría la utilización de catálogos de tópicos y conduce a una racionalización mayor de la aplicación de los tópicos a través de estas técnicas. En este sentido, hay que tener en cuenta que la creación de técnicas jurídicas (como la ponderación, el principio de proporcionalidad, de confianza legítima o el precedente administrativo y judicial) se adscribe a la tradición tópica y no a la sistemática; y que explica una parte pequeńa de las formas de solución de los problemas jurídicos.

En una primera aproximación puede parecer que estas técnicas tópicas son similares a otras herramientas que se han descrito en la metodología tradicional, como es el caso de los sistemas móviles. Sin embargo, los elementos de un sistema móvil tienen diferente peso y pueden ser intercambiables (al respecto, WESTERHOFF, 1991: 15 ss.); cosa que no parece que pueda desprenderse de la forma en que se articulan los tests o técnicas tópicas. No obstante, en esta línea Viehweg afirma que los principios que rigen la aplicación del Derecho de daños cumplen una función tópica, porque ninguno se sitúa por encima de otros (VIEHWEG, 2007: 164 ss.; MORELLI, 2002: 75).

\subsection{Aforismos y máximas en el Derecho público}

71. Junto a los conceptos con función tópica y a las técnicas tópicas de resolución de problemas, es posible identificar una tercera manifestación de la tradición tópica en el Derecho público: la utilización de aforismos, máximas o tópicos (entendidos en sentido vulgar: como una idea extendida y comúnmente aceptada). Así, no es extraño que en la argumentación para resolver un problema se invoque una máxima jurídica o aforismo que, normalmente, tienen su origen en los catálogos medievales de reglas jurídicas -aunque su formulación en latín pueda llevar a pensar en muchos casos que su origen está en el Derecho romano-. Se trataría de tópicos de carácter material, frente a los tópicos de carácter formal [supra $\$ \$ 34$ ss.].

Por ejemplo, en el Derecho público se alude a la regla de venire contra factum proprium non valet (DÍEZ, 2018b: 61 ss.) o a la teoría del enriquecimiento injusto (REBOLLO, 1995: passim). Otro ejemplo de aforismo jurídico de gran importancia es la máxima lex specialis derogat legi generali, que ordena la relación entre las fuentes incluso por encima del criterio de que la ley posterior deroga la ley anterior que, aunque también tiene su origen en otro aforismo (lex posterior derogat priori), está recogido expresamente en el ordenamiento jurídico (art. 2 Código Civil) (DÍEZPICAZO, 1990: 361 ss.).

72. Los aforismos se utilizan en muchas ocasiones como máximas jurídicas que guían la interpretación, normalmente del juez, pero también de la Administración 
-así, por ejemplo, el aforismo in claris non fit interpretatio-. Su función es justificar una concreta interpretación de las normas o reforzar las pretensiones de alguna de las partes (CARBONELL y LETELIER, 2011: 164). En ocasiones, su tarea va más allá de la mera interpretación o refuerzo y se convierten en fórmulas con las que se pretenden dar soluciones previamente fijadas a ciertos casos. A diferencia de los tópicos formales, estos aforismos no ayudan al análisis de un problema. Muestran una solución prestablecida, que suele estar vinculada a un sentimiento intuitivo de justicia o al sentido común -por ejemplo, en la máxima "quien puede lo más puede lo menos" o la regla prior in tempore potior in iure-. Por esa razón, puede entenderse que estos aforismos se alejan de la tradición de la tópica clásica.

73. Quizás por ello, su contenido no siempre es compatible con las exigencias del Derecho positivo, especialmente en el ámbito del Derecho público. Estas máximas se consolidaron, en general, en el ámbito del Derecho privado y tienen una dudosa legitimidad en la actualidad. Los aforismos se acercan a la costumbre porque requieren un elemento de consensus omnium -que puede acercarse a la communis opinio de la costumbre- que exige cierta estabilidad a lo largo del tiempo y la identificación de una comunidad a la que atribuir la capacidad para aceptar o rechazar los tópicos y las conclusiones derivadas del debate con base en los mismos. Únicamente su utilización habitual por los más altos tribunales convierte a estos aforismos en jurisprudencia, cuyo valor ya tendría un encaje aceptable en el ordenamiento jurídico, a pesar de que su convivencia con el Derecho positivo no sea siempre pacífica (SANTIAGO, 2019).

74. En este sentido, hay que tener en cuenta el frecuente uso que se hace de estos aforismos en el contexto de la globalización jurídica (GARRIGUES, 2003: 17). Su origen habitual en el Derecho romano y, normalmente, en el ius commune refuerza su capacidad para persuadir sobre su idoneidad para buscar soluciones aplicables más allá de las fronteras del Estado, incluso en países con tradiciones jurídicas diversas. Ahora bien, ya se ha señalado que estos aforismos son tópicos materiales que contienen verdaderas soluciones jurídicas y que no actúan como tópicos en sentido estricto con una función de invención o creación de premisas. Por esa razón, puede ser peligroso que la invocación genérica de estos aforismos se sustituya por una aplicación racional de las normas juridicas que, en muchas ocasiones ya resuelven los problemas que se pretenden reconducir a través de estas máximas jurídicas. El proceso de construcción de un Derecho global no requiere una retroacción en el tiempo borrando los últimos trescientos años de historia, sino un proceso de abstracción y de búsqueda racional de soluciones jurídicas que aparecen en los distintos ordenamientos jurídicos (en sentido opuesto, PEREIRA-MENAUT, 2001: 45-47).

Así, por ejemplo, es habitual que se utilice la máxima patere legem quam ipse feciste en el ámbito europeo (PEREIRA-MENAUT, 2001: 37 ss.), cuando existen técnicas jurídicas -por ejemplo, el precedente o la autovinculación en Alemania (Selbstbindung)- que permiten racionalizar las respuestas que deben darse a ese tipo de supuestos y que se pueden reconducir a mandatos del Derecho positivo (igualdad y protección de la confianza, entre otros) (DÍEZ, 2008). Es posible que el origen histórico de esas reglas esté en el aforismo latino, pero su aplicación para resolver problemas actuales requiere, en la medida de lo posible, una reconducción a soluciones que cuentan con un soporte en el Derecho positivo. 
75. Junto a los aforismos y las máximas, aparecen también en Derecho público los lugares comunes, en sentido amplio, que aluden a ideas comúnmente aceptadas y que no tienen, necesariamente, un soporte en el ordenamiento jurídico. Tampoco se trata de tópicos con una función analítica-tópicos formales-, sino que logran persuadir a través de la apelación a un consenso colectivo previo en torno a una idea. La utilización de estos tópicos es habitual en la jurisprudencia y puede llevar a deformar la premisa originaria (RODRÍGUEZ DE SANTIAGO, 2002: 1292). Su utilización plantea, así, problemas comunes a los que se encuentran en los aforismos, puesto que en ambos casos se está ante tópicos materiales y no formales.

Así, por ejemplo, la idea de que el ámbito propio del reglamento independiente es el de la organización administrativa permite resolver un problema prescindiendo de la invocación de las normas aplicables del ordenamiento jurídico y sin ubicar el problema en un contexto sistemático, con una visión de conjunto (en detalle, RODRÍGUEZ DE SANTIAGO, 2002: 1292 ss.).

\section{NOTA BIBLIOGRÁFICA}

Aulius AARNIO, Denkweisen der Rechtswissenschaft, Springer, Wien-New York, 1979.

Luis ARROYO y Dolores UTRILLA (dirs.), La administración de la escasez, Marcial Pons, Madrid, 2015.

Manuel ATIENZA, «El derecho como argumentación», Isegoría, núm. 21, 1999, pp. 37-47.

- Curso de argumentación jurídica, 1.a reimpr., Trotta, Madrid, 2013.

ARISTÓTELES, Tratados de lógica, Porrúa, México D. F., 2011.

Javier BARNES, "Jurisprudencia constitucional sobre el principio de proporcionalidad en el ámbito de los derechos y libertades", Cuadernos de Derecho Público, núm. 5, 1998, pp. 333-370.

Ramón BELTRÁN CALFURRAPA, "La tópica jurídica y su vinculación argumentativa con el precedente y la jurisprudencia", Revista de Derecho de la Pontificia Universidad Católica de Valparaiso, XXXIX, 2012, pp. 587-606.

Harold J. BERMAN, La formación de la tradición jurídica de Occidente, 1. a reimpr., Fondo de Cultura Económica, México D. F., 2001.

Arturo BERUMEN CAMPOS, "Ponderación de principios y tópica jurídica", Boletín mexicano de Derecho comparado, vol. 48 núm. 143, 2015, pp. 531-546.

Jürgen BLÜHDORN, "Kritische Bemerkungen zu Theodor Viehwegs Schrift: Topik und Jurisprudenz", Tijdschrift voor Rechtsgeschiedenis, 269, 1970, pp. 269-314.

Arno BOKELOH, Der Beitrag der Topik zur Rechtsgewinnung, Dissertation, Georg-August-Universitätzu Götingen, Göttingen, 1973.

Ernst Wolfgang BÖCKENFÖRDE, «Rez. Topik und Jurisprudenz, Theodor Viehweg, 2. Durchgesehene Auflage, München, 1963, Beck», Der Staat, 3. Band, 1964, p. 517.

- "Die Methoden der Verfassungsinterpretation - Bestandaufnahme und Kritik", NJW, Heft 46, 1976, pp. 2089-2099.

Johann BRAUN, Deduktion und Invention, Mohr Siebeck, Tübingen, 2016.

Claus-Wilhelm CANARIS, Systemdenken und Systembegriff in der Jurisprudenz entwickelt am Beispiel des deutschen Privatrechts, 2. überarbeitete Aufl., Duncker \& Humblot, Berlin, 1983.

Flavia CARBONELL BELLOLIO y Raúl LETELIER WARTENBERG, "Principios jurídicos e interpretación democrática del Derecho", en Flavia Carbonell, Rodrigo Coloma y Raúl Letelier (coords.), Principios jurídicos. Análisis y crítica, Abeledo Perrot, Thomson Reuters, Santiago de Chile, 2011, pp. 155-183.

CICERÓN, La invención retórica, Gredos, Madrid, 1997.

- Tópicos a Cayo Trebacio, CreateSpace, Wroclaw, 2017. 
Juan Omar COFRÉ LAGOS, "Lógica, tópica y retórica al servicio del Derecho", Revista de Derecho (Valdivia), vol. XIII, 2002, pp. 27-40.

Helmut COING, "Über einen Beitrag zur Rechtswissenschaftlichen Grundlagenforschung”, Band 41, Heft 3, 1955, pp. 436-444.

— Grundzüge der Rechtsphilosophie, 5. Auflage, Walter de Gruyter \& CO, Berlin, 1993.

Uwe DIEDERICHSEN, "Topisches und systematisches Denken in der Jurisprudenz", NJW, Heft 16, 1966, pp. 697-705.

Luis María DÍEZ-PICAZO, La derogación de las leyes, Civitas, Madrid, 1990.

Silvia DÍEZ SASTRE, El precedente administrativo, Marcial Pons, Madrid, 2008.

- La formación de conceptos en el Derecho público, Marcial Pons, Madrid, 2018a.

- "La doctrina de los actos propios en el Derecho administrativo", en Diego MARÍN-BARNUEVO FABO (dir.), La doctrina de los actos propios en el Derecho tributario, Civitas, Thomson-Reuters, Cizur Menor, 2018b, pp. 31-81.

Gabriel DOMÉNECH PASCUAL, "Por qué y cómo hacer análisis económico del Derecho", RAP, 195, 2014, pp. 99-133.

Rafael DOMINGO, “Introducción”, en Domingo, Rafael (dir.), Principios de Derecho global. Aforismos jurídicos comentados, Thomson Reuters, Aranzadi, Cizur Menor, 2003, pp. 19-24.

Josef ESSER, Grundsatz und Norm in der richterlichen Fortbildung des Privatrechts, 4. Auflage, Mohr Siebeck, Tübingen, 1990.

Alfredo GALLEGO ANABITARTE, "Sobre el comentario constitucional. Técnica y método", Revista de Estudios Políticos, núm. 121, 1962, pp. 137-167.

Juan Antonio GARCÍA AMADO, "Retórica, argumentación y derecho", Isegoría, núm. 21, 1999, pp. 131-147.

— "Abwägung versus normative Auslegung? Kritik der Anwendung des Verhältnismäßigkeitsprinzips als Mittel juristischer Methodik", Rechtstheorie, 1/40, 2009, pp. 1-42.

— "Principios, reglas y otros misteriosos pobladores del mundo jurídico. Un análisis (parcial) de la Teoría de los derechos fundamentales de Robert Alexy", en Flavia CARBONELL, Rodrigo COLOMA y Raúl LETELIER (coords.), Principios jurídicos. Análisis y crítica, Abeledo Perrot, Thomson Reuters, Santiago de Chile, 2011, pp. 28-64.

- Teorías de la tópica jurídica, 1. a ed. digital, Palestra, Lima, 2019.

Eduardo GARCÍA DE ENTERRÍA MARTÍNEZ-CARANDE, "Reflexiones sobre la Ley y los principios generales del Derecho en el Derecho Administrativo", RAP, núm. 40, 1963, pp. 189-222.

— "Prólogo", en Theodor Viehweg, Tópica y Jurisprudencia, trad. por Luis Díez-Picazo, reimpr. 2006, Civitas, Madrid, 2007, pp. 11-23.

Antonio GARRIGUES WALKER, en DOMINGO, Rafael (dir.), Principios de Derecho global. Aforismos juridicos comentados, Thomson Reuters, Aranzadi, Cizur Menor, 2003, pp. 17-18.

Marina GASCÓN ABELLÁN y Alfonso J. GARCÍA FIGUEROA, La argumentación en el Derecho, 2. ${ }^{a}$ ed. corregida, Palestra, Lima, 2005.

Patrick HILBERT, Systemdenken im Verwaltungsrecht-und Verwaltungsrechtswissenschaft, Mohr Siebeck, Tübingen, 2015.

Norbert HORN, "Zur Bedeutung der Topiklehre Theodor Viehwegs für eine einheitliche Theorie des juristischen Denkens", NJW, Heft 14, 1967, pp. 601-608.

Rudolf von JHERING, El espiritu del Derecho romano, abreviatura por Fernando Vela, Marcial Pons, Madrid, 2007.

Ernst A. KRAMER, "Topik und Rechtsvergleichung”, Rabels Zeitschrift für ausländisches und internationales Privatrecht, 33. Jahrgang, 1969, pp. 1-16.

Martin KRIELE, Theorie der Rechtsgewinnung, entwickelt am Problem der Verfassungsinterpretation, 2. Auflage, Duncker \& Humblot, Berlin, 1976.

Karl LARENZ, Metodología de la Ciencia del Derecho, 2. ${ }^{\mathrm{a}}$ ed., Ariel, Barcelona, 2001.

Agnes LAUNHARDT, Topik und Rhetorische Rechtstheorie. Eine Untersuchung zu Rezeption und Relevanz der Rechtstheorie Theodor Viehweg's, Peter Lang, Frankfurt a. M., 2010.

Raphael LEMKIN, "Genocide”, American Scholar, 15/2, 1946, pp. 227-230. 
Neil MACCORMICK, “Retórica y Estado de Derecho”, trad. por Isabel Lifante, Isegoría, núm. 21, 1999, pp. 5-21.

Manuel MANSON T., "Recasens Siches y la lógica jurídica formal", Revista chilena de Derecho, vol 4, núms. 1-6, 1977, pp. 196-212.

Luis MEDINA ALCOZ, Libertad y autoridad en el Derecho administrativo. Derecho subjetivo e interés legitimo: una revisión, Marcial Pons, Madrid, 2016.

Mariano G. MORELLI, "Pensar el Derecho desde el problema. Theodor Viehweg: tópica y sistema en la historia del Derecho", Investigación y docencia, núm. 35, 2002, pp. 57-90.

Thomas M. J. MÖLLERS, Juristische Methodenlehre, 2. Auflage, C. H. Beck, München, 2019.

Alejandro NIETO GARCÍA, Crítica de la razón jurídica, Trotta, Madrid, 2007.

Bernd H. OPPERMANN, Die Rezeption des nordamerikanischen Rechtsrealismus durch die deutsche Topikdiskussion, DifoDruck, Frankfurt a. M., 1985.

Fritz OSSENBÜHL, "Vertrauensschutz im sozialen Rechtsstaat", DÖV, 1972, pp. 25-36.

Gerhard OTTE, "Zwanzig Jahre Topik-Diskussion: Ertrag und Aufgaben”, Rechtstheorie, 1. Band, Heft 1/2, 1970, pp. 183-197.

Gerardo PEREIRA-MENAUT, Tópica. Principios de Derecho y Máximas Jurídicas Latinas, Arcana, Veri, Santiago de Compostela, 2001.

Chaim PERELMAN, Justice, Law and Argument, D. Reidel Publishing Company, Dordrecht-BostonLondon, 1980.

Manuel REBOLLO PUIG, El enriquecimiento injusto de la Administración pública, Marcial Pons, Madrid, 1995.

Klaus REHBOCK, Topik und Recht, eine Standortanalyse unter besonderer Berücksichtigung der aristotelischen Topik, Verlag V. Florenz, München, 1988.

Franz REIMER, Juristische Methodenlehre, Nomos, Baden-Baden, 2016.

Gregorio ROBLES, "La decisión en el Derecho y la tópica jurídica", Boletín mexicano de Derecho comparado, 1985, pp. 101-135.

José María RODRÍGUEZ DE SANTIAGO, La ponderación de bienes e intereses en el Derecho administrativo, Marcial Pons, Madrid, 2000.

— "Sistema, tópica y argumentación en la metodología del Derecho administrativo actual", en Panorama jurídico de las Administraciones Públicas en el siglo XXI. Homenaje al Profesor Eduardo Roca Roca, MAP, INAP, BOE, Madrid, 2002, pp. 1281-1308.

- Metodología del Derecho administrativo. Reglas de racionalidad para la adopción y el control de la decisión administrativa, Marcial Pons, Madrid, 2016.

Manuel Jesús RODRÍGUEZ PUERTO, "Tópica y humanismo jurídico", Anuario de Filosofía del Derecho, núm. XVIII, 2001, pp. 363-383.

Philippe SANDS, Calle Este-Oeste: Sobre los origenes de "genocidio" y "crimenes contra la humanidad", 2. ${ }^{\text {a }}$ ed., Anagrama, Barcelona, 2018.

Diana SANTIAGO IGLESIAS, "La eficacia de la jurisprudencia en el ordenamiento jurídico administrativo", REDA, núm. 202, 2019 pp.163-196.

Frederick SCHAUER, Las reglas en juego. Un examen filosófico de la toma de decisiones basada en reglas, en el derecho y en la vida cotidiana, Marcial Pons, Madrid, 2004.

Eberhard SCHMIDT-ASSMANN, La teoría general del Derecho Administrativo como sistema, trad. por Mariano Bacigalupo Saggese, Javier Barnes, Javier García Luengo, Ricardo García Macho, Alejandro Huergo Lora, José María Rodríguez de Santiago, Blanca Rodríguez Ruiz, Germán Valencia y Francisco Velasco Caballero, INAP, Marcial Pons, Madrid, 2003.

Jan SCHRÖDER, Recht als Wissenschaft. Geschichte der juristischen Methodenlehre in der Neuzeit (15001933), 2. Auflage, C. H. Beck, München, 2012.

Thomas-M. SEIBERT, "Topik als Systematisierung von Aussagesätzen. Gegenthese zu Eike von Savigny: Zur Rolle der deduktiv-axiomatischen Methode in der Rechtswissenschaft", ARSP, 1973, pp. 37-58.

Mathieu TOUZEIL-DIVINA, Dix mythes du droit public, LGDJ, Issy-les-Moulineaux Cedex, 2019.

Francisco VELASCO CABALLERO, Derecho público más Derecho privado, Marcial Pons, Madrid, 2014. 
— "Metodología comparativa para el Derecho Administrativo", REDA, núm. 200, 2019, pp. 51-76.

Theodor VIEHWEG, Rechtsphilosophie und rhetorische Rechtstheorie. Gesammelte kleine Schriften, Nomos, Baden-Baden, 1995.

- Tópica y Jurisprudencia, trad. por Luis Díez-Picazo, reimpr. 2006, Civitas, Madrid, 2007.

Otta WEINBERGER, “Topik und Plausibilitätsargumentation”, ARSP, 1973, pp. 17-37.

Rudolf WESTERHOFF, Die Elemente des Beweglichen Systems, Duncker \& Humblot, Berlin, 1991.

Reinhold ZIPPELIUS, "Problemjurisprudenz und Topik", NJW, Heft 48, 1967, pp. 2229-2234. 